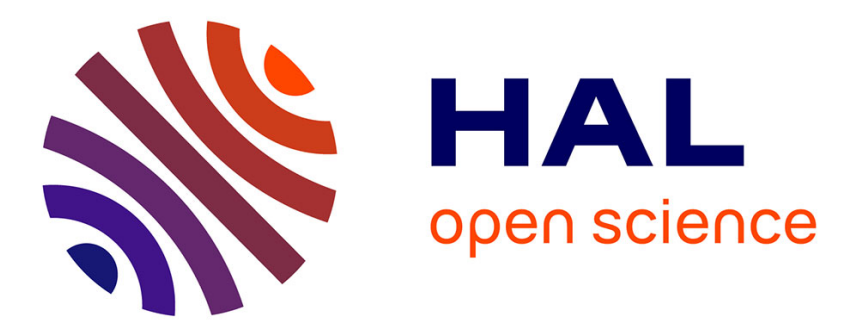

\title{
Synthesis of bridged aza-rebeccamycin analogues
}

S. Messaoudi, Fabrice Anizon, B. Pfeiffer, M. Prudhomme

\section{To cite this version:}

S. Messaoudi, Fabrice Anizon, B. Pfeiffer, M. Prudhomme. Synthesis of bridged aza-rebeccamycin analogues. Tetrahedron, 2005, pp.7304-7316. 10.1016/j.tet.2005.04.043 . hal-00125815

\section{HAL Id: hal-00125815 \\ https://hal.science/hal-00125815}

Submitted on 5 Mar 2007

HAL is a multi-disciplinary open access archive for the deposit and dissemination of scientific research documents, whether they are published or not. The documents may come from teaching and research institutions in France or abroad, or from public or private research centers.
L'archive ouverte pluridisciplinaire HAL, est destinée au dépôt et à la diffusion de documents scientifiques de niveau recherche, publiés ou non, émanant des établissements d'enseignement et de recherche français ou étrangers, des laboratoires publics ou privés. 


\title{
Synthesis of bridged aza-rebeccamycin analogues
}

\author{
Samir Messaoudi, ${ }^{\mathrm{a}}$ Fabrice Anizon, ${ }^{\mathrm{a}}$ Bruno Pfeiffer $^{\mathrm{b}}$ and Michelle Prudhomme ${ }^{\mathrm{a}}{ }^{*}$ \\ ${ }^{a}$ Université Blaise Pascal, Synthèse et Etude de Systèmes à Intérêt Biologique, UMR 6504 du CNRS, 63177 Aubière, France \\ bInstitut de Recherches Servier, Division Recherche Cancérologie, 125 Chemin de ronde, 78290 Croissy sur Seine, France
}

\begin{abstract}
The syntheses of rebeccamycin analogues possessing a 7-azaindole moiety instead of an indole unit, and with both indole and azaindole moieties linked to the carbohydrate are described. In these bridged aza compounds, the oxygen of the pyranose heterocycle is oriented towards either the indole, or the azaindole unit. In these series, compounds bearing a free imide nitrogen were synthesized by coupling the corresponding aglycones with a sugar pre-tosylated in 2-position via a Mitsunobu reaction. To obtain a precursor for bridged aza-rebeccamycin analogues substituted in 6-position on the sugar moiety, a 2,6-ditosylated sugar was used.
\end{abstract}

\section{Introduction}

Rebeccamycin, isolated from cultures of Saccharothrix aerocolonigenes, contains an indolocarbazole framework, an imide upper heterocycle and a sugar part linked to one of the indole nitrogens like other natural products such as some tjipanazoles E, F1 and F2 and AT2433-A1 and B1 but unlike staurosporine and $\mathrm{UCN}-01$ in which the carbohydrate moiety is linked to both indole nitrogens (Fig. 1). ${ }^{1-4}$ Rebeccamycin is a topoisomerase I inhibitor without inhibitory properties toward kinases such as CDK1/cyclinB, CDK5/p25 and PKC whereas staurosporine and UCN-01 are not topoisomerase I poisons but exhibit inhibitory properties against a variety of kinases. ${ }^{5-7}$ In the course of structure-activity relationship studies on rebeccamycin analogues, we have synthesized 7-aza-rebeccamycin analogues in which one or both indole moieties have been replaced by a 7 -azaindole unit. ${ }^{8,9}$ When only one azaindole was introduced, the sugar part was linked either to the indole or to the azaindole (Fig. 2). Important differences in DNA binding properties and in topoisomerase I poisoning were observed between the two series. Compounds with the sugar moiety attached to the indole moiety exhibited strong DNA binding and topoisomerase I inhibitory properties whereas with compounds in which the sugar was attached to the azaindole, DNA binding and topoisomerase I poisoning were highly weakened or completely abolished. However, compounds in both series could exhibit strong in vitro cytotoxicities toward some tumor cell lines with $\mathrm{IC}_{50}$ values in the nanomolar range, suggesting other biological targets

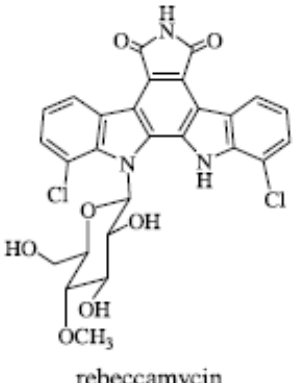

rebeccamycin

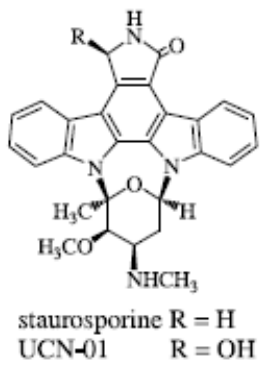

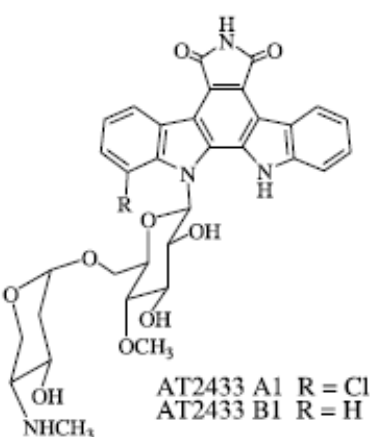

Figure 1. Chemical structures of the bacterial metabolites rebeccamycin, staurosporine, UCN-01, AT2433 A1 and B1.

Keywords: Staurosporine; Rebeccamycin; 7-Azaindole; Antitumor compounds; Enzyme inhibitors.

* Corresponding author. Tel.: +3347340 71 24; fax: +3347340 77 17; e-mail: Michelle.PRUDHOMME@ univ-bpclermont.fr 

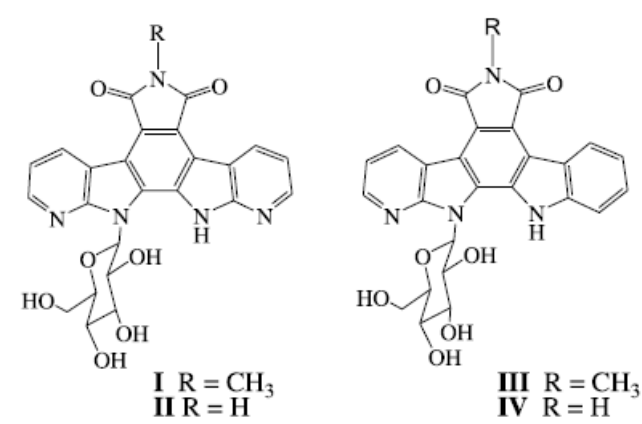

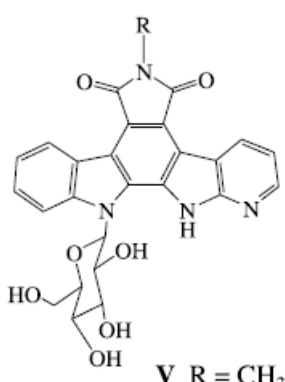

$\mathrm{V} R=\mathrm{CH}_{3}$
$\mathrm{VI}=\mathrm{H}$

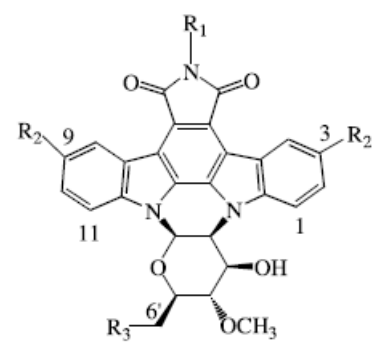

VII $\mathrm{R}_{1}=\mathrm{CH}_{3}, \mathrm{R}_{2}=\mathrm{R}_{3}=\mathrm{H}$

VIII $R_{1}=R_{2}=R_{3}=H$

Figure 2. Aza-rebeccamycin analogues previously described.

than DNA and topoisomerase I for compounds in which the sugar is linked to the azaindole. To get an insight into the structural parameters inducing enzyme selectivity, we have synthesized staurosporine analogues from rebeccamycin by coupling the sugar moiety to the second indole nitrogen in non aza series at first and recently, one $N$-methylated compound has been prepared in 7-azaindole series. ${ }^{10-12}$ In a previous brief communication, we described the synthesis of the 7-aza staurosporine analogue $\mathbf{5}$ with the sugar attached to both indole and azaindole nitrogens, with a methyl group on the imide nitrogen and with the oxygen heteroatom of the sugar ring oriented toward the indole unit

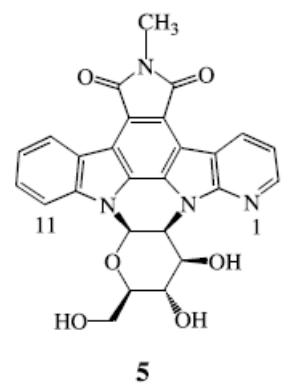

(Fig. 2). ${ }^{12}$ This compound was synthesized by coupling an $\alpha$-1-chloro-glucose on the $N$-methylated indolocarbazole aglycone in the presence of a phase transfer catalyst. As deduced from the crystal structures of staurosporine in complex with various kinases, a free nitrogen in the upper heterocycle seems to be necessary to establish a hydrogen bond with the carbonyle of glutamate 81 in the ATP binding pocket of the kinases. ${ }^{13,14}$ In this paper, the syntheses of new 7-aza bridged compounds, without the methyl group on the imide nitrogen and with the oxygen of the sugar ring oriented either toward the indole or toward the azaindole moiety, are reported. The replacement of an indole moiety
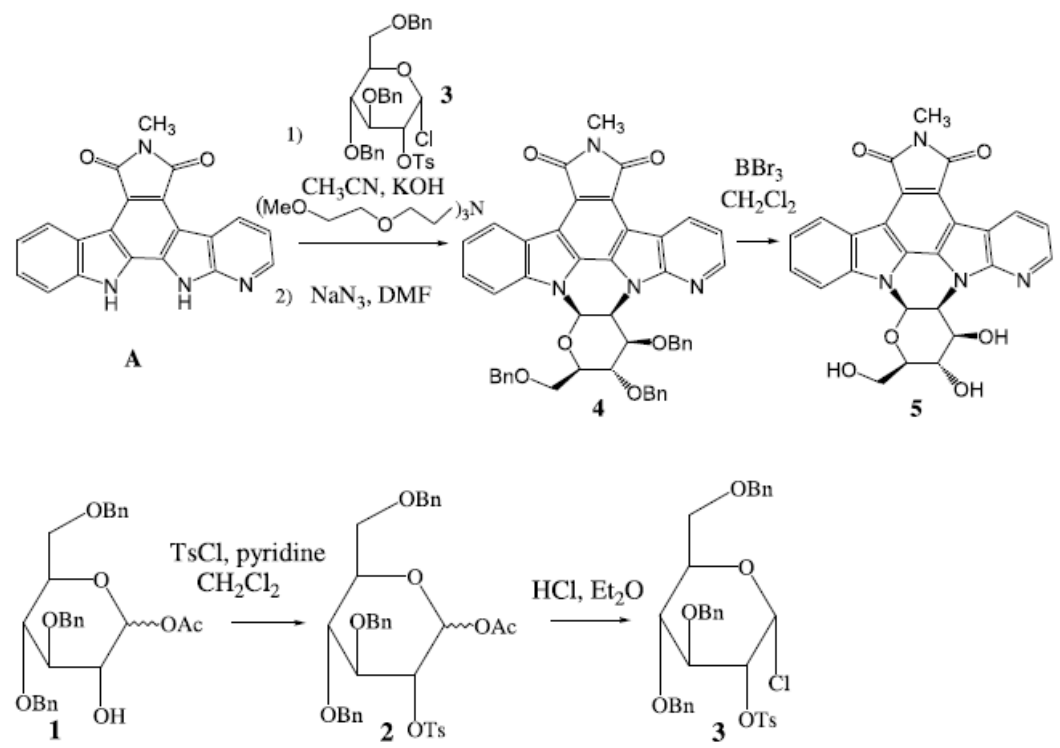

Scheme 1. Synthetic scheme for compound $\mathbf{5}$ 
by an azaindole in the bridged series could increase the affinity for the binding site of the target enzyme(s) and modify the electronic distribution on the aromatic framework and the lipophilicity. Because, it has been shown that substitutions in 6-position of the sugar unit can modify the biological target ${ }^{15,16}$, we use a sugar unit ditosylated in 2and 6-positions allowing access to bridged aza compounds substituted in 6-position of the sugar moiety with an azido group, a precursor for amino and amido substituents.

\section{Results and discussion}

\subsection{Chemistry}

The synthesis of compound $\mathbf{5}$ is outlined in Scheme 1. The<smiles>COC(=O)N1C(=O)C(c2c[nH]c3ccccc23)=C(c2c[nH]c3ncccc23)C1=O</smiles>
$\mathrm{hv}, \mathrm{I}_{2}$ benzene C

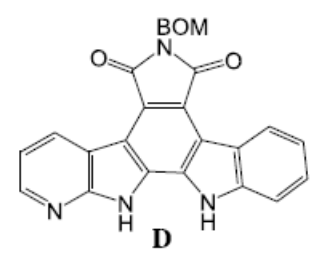

chloro sugar $\mathbf{3}$ was prepared from acetylated compound $\mathbf{1}$ which could be obtained from the commercial triacetylated glycal as described in literature. ${ }^{17-19}$ Tosylation of 1 yielded tosylate 2 as a mixture of both $\alpha$ and $\beta$ anomers, which was further treated with $\mathrm{HCl}$ gas to give the $\alpha$-chloro anomer 3 . $^{12}$ This chloro sugar was coupled to the aglycone $\mathbf{A}^{20}$ using potassium hydroxide and a phase transfer catalyst to yield the required coupling product, which was further treated with sodium azide to give the bridged compound $\mathbf{4}$ formed via a nucleophilic attack of the deprotonated azaindolic nitrogen on the carbon bearing the tosyl group. Elimination of the benzyl protecting groups of the sugar moiety was carried out using boron tribromide. For the synthesis of compound 12 (Scheme 3), the same procedure as described for the synthesis of $\mathbf{5}$ was tried from aglycone $\mathbf{D}$, which was obtained from $\mathbf{C}^{9}$ by oxidative photocyclization (Scheme 2). However, the coupling reaction with the chloro sugar $\mathbf{3}$ did not work. A Mitsunobu reaction was then performed from aglycone $\mathbf{B}^{9}$ and sugar $\mathbf{6}$ prepared from $\mathbf{2}$ by reaction with $\mathrm{MeONa} / \mathrm{MeOH}$ in $\mathrm{THF}$ (Scheme 3). Compound 7 was obtained in $88 \%$ yield. After deprotection of the azaindole nitrogen, oxidative photocyclization in the presence of iodine gave 9 in $62 \%$ yield. Reaction of 9 with sodium azide led to the bridged compound $\mathbf{1 0}$ in $72 \%$ yield. Unlike for compound 4, debenzylation of $\mathbf{1 0}$ using boron

Scheme 2. Photocyclization of aglycone C.
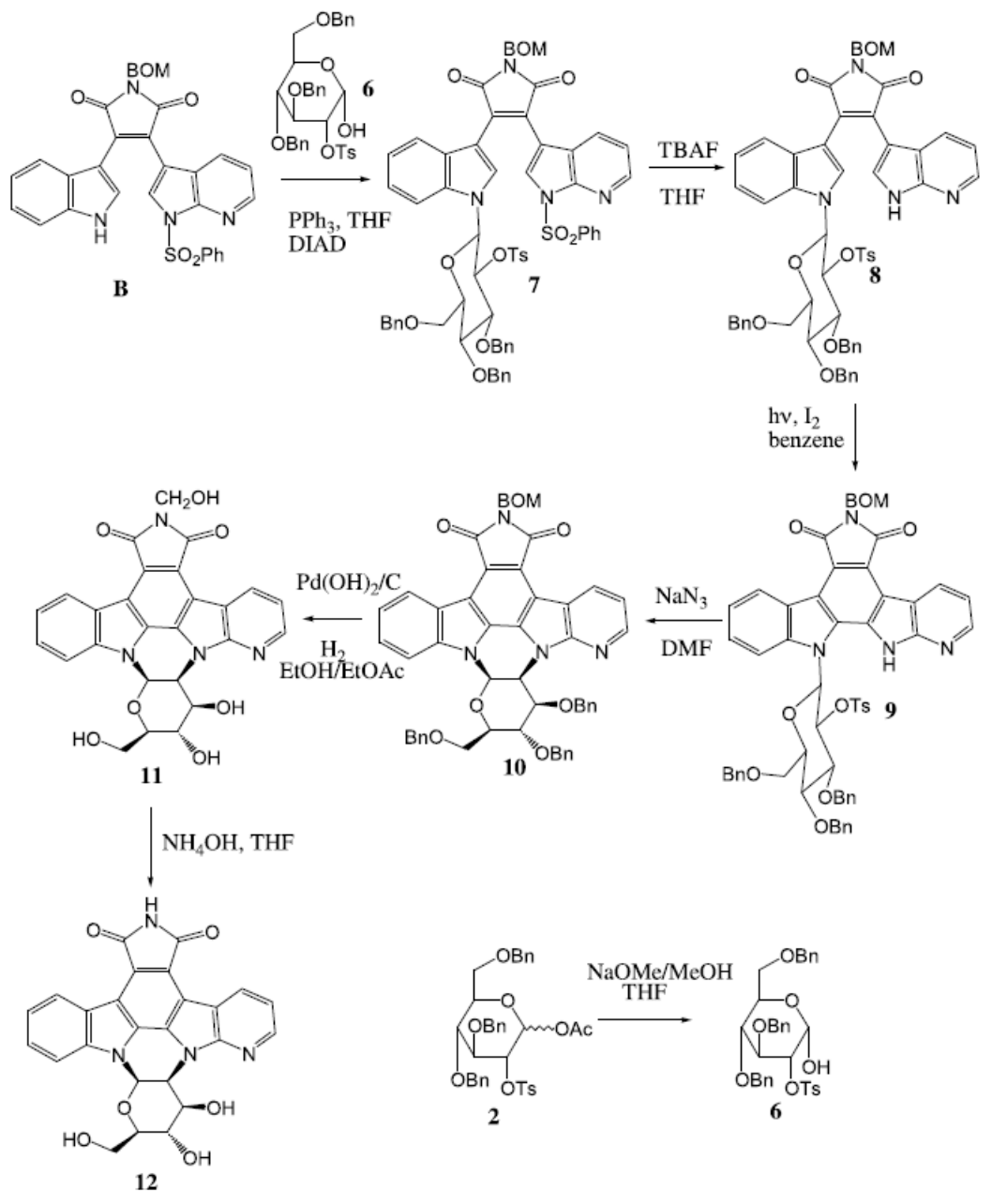

Scheme 3. Synthesis of compound 12. 

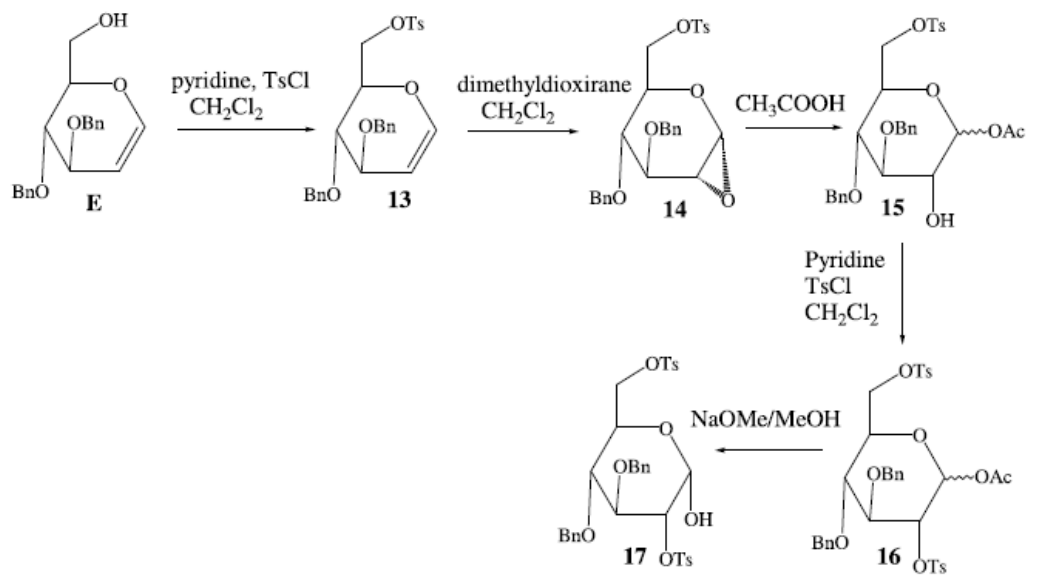

Scheme 4. Synthesis of di-tosylated sugar 17.

tribromide gave an inexploitable mixture. Removal of the protective groups was achieved in two steps: hydrogenolysis with $\mathrm{Pd}(\mathrm{OH})_{2} / \mathrm{C}$ as the catalyst leading to 11 in $52 \%$ yield, followed by aminolysis giving the required compound $\mathbf{1 2}$ in $71 \%$ yield.

To introduce substituents selectively in $6^{\prime}$ position on the

sugar moiety of $\mathbf{1 2}$, the Mitsunobu reaction was carried out using 2,6-ditosyl-sugar 17, which was prepared from glycal $\mathbf{E}$ as shown in Scheme 4.

Glycal $\mathbf{E}$ was prepared according to known procedures. ${ }^{21}$ Tosylation of $\mathbf{E}$ at 6-position led to compound $\mathbf{1 3}$. Epoxidation performed using dimethyldioxirane provided

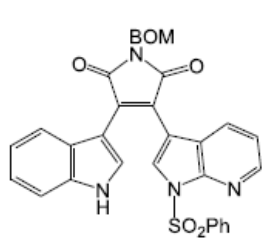

B

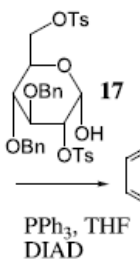

DIAD$$
\mathrm{TsO}
$$

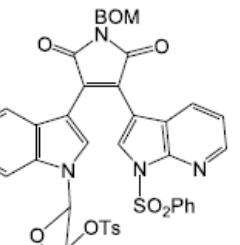

18

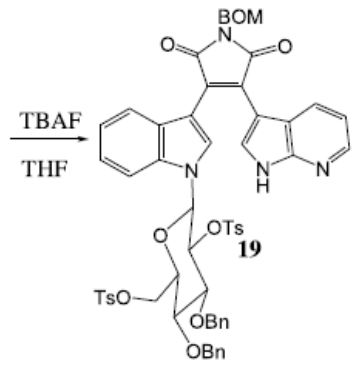

$\mathrm{hv}, \mathrm{I}_{2}$

benzene<smiles>N#CC[C@H]1O[C@@H]2C([C@H](O)[C@@H]1O)n1c3ccccc3c3c4c(c5c6cccnc6n2c5c31)C(=O)N(CO)C4=O</smiles>

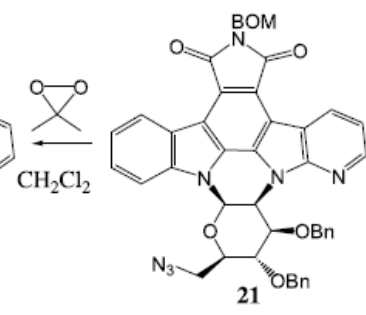

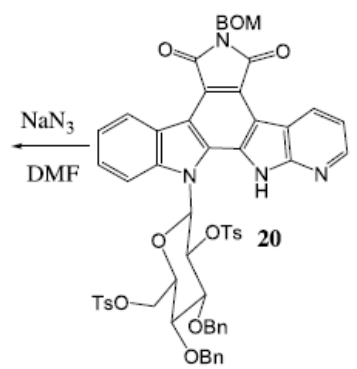

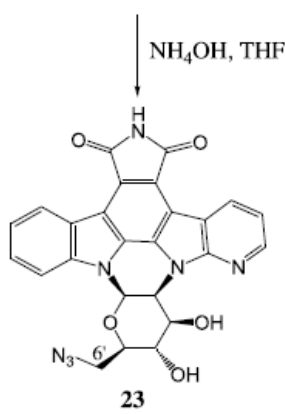

Scheme 5. Synthesis of $6^{\prime}$-azido compound $\mathbf{2 3}$. 
the anhydro sugar $\mathbf{1 4}$ as the major isomer. Reaction of $\mathbf{1 4}$ with glacial acetic acid gave compound $\mathbf{1 5}$ in $77 \%$ yield as a mixture of both $\alpha$ and $\beta$ anomers in $0.3: 2$ ratio, respectively. Tosylation of $\mathbf{1 5}$ led to a mixture of both $\alpha$ and $\beta$ anomers in $1: 3.9$ ratio, respectively, in only $24 \%$ yield. $31 \%$ of the unreacted $\beta$ anomer was recovered. The final step was deacetylation with sodium methoxide/methanol affording 17 in $66 \%$ yield. The Mitsunobu reaction between 17 and aglycone $\mathbf{B}$ led to compound $\mathbf{1 8}$ in 52\% yield. Deprotection of the azaindole nitrogen using tetrabutylammonium fluoride gave 19 in $83 \%$ yield. Compound 19 was further photocyclized to give $\mathbf{2 0}$. Reaction of $\mathbf{2 0}$ with sodium azide in DMF induced the coupling of the sugar part with the azaindole nitrogen and concomitant substitution at $6^{\prime}$ position to give $\mathbf{2 1}$ (Scheme 5). Contrary to compound $\mathbf{1 0}$, debenzylation by hydrogenolysis could not be achieved with compound 21. A mixture of compounds reduced on the aromatic rings was obtained. Debenzylation carried out using dimethyldioxirane $e^{22,23}$ afforded the required compound $\mathbf{2 2}$ in $45 \%$ yield. Removal of the hydroxymethyl substituent by aminolysis gave $\mathbf{2 3}$ in $77 \%$ yield.

Because in non-bridged aza rebeccamycins, important differences in the biological activities were observed between compounds in which the carbohydrate was linked either to the indole nitrogen or to the azaindole unit, bridged compounds with a nitrogen atom in 11-position instead of 1-position in the azaindolocarbazole were also synthesized (Scheme 6). A similar sequence of reactions as for the synthesis of $\mathbf{1 2}$ was performed from aglycone $\mathbf{F}^{9}$ until elimination of the benzenesulfonyl protective group leading to $\mathbf{2 5}$. Photocyclization of $\mathbf{2 5}$ in the presence of iodine did not afford the required compound $\mathbf{2 6}$, only degradation was observed. Cyclization was successfully achieved in $56 \%$ yield using palladium triflate in DMF at $90{ }^{\circ} \mathrm{C}$ according to a method described by Faul et al. ${ }^{24}$ for the synthesis of rebeccamycin. Reaction of $\mathbf{2 6}$ with sodium azide led to $\mathbf{2 7}$ in $93 \%$ yield. Debenzylation carried out using trifluoroacetic acid or dimethyldioxirane or by hydrogenolysis proved to be unsuccessful. The required compound $\mathbf{2 8}$ was finally obtained in $27 \%$ yield by debenzylation with boron tribromide followed by aminolysis.

\section{Conclusion}

In conclusion, we have developed methods to synthesize bridged aza-rebeccamycin analogues from 2-O-tosyl-glucopyranose. Both analogues in which the anomeric carbon of the sugar part is linked to either the azaindole or the indole moiety have been synthesized. The use of 2,6- $O$-ditosylglucopyranose, in the Mitsunobu reaction, allowed the introduction of an azido group in $6^{\prime}$-position. This method can also be applied for introducing a wide range of substituents in 6-position of the sugar moiety. The cytotoxicities and the inhibitory activities of these new compounds toward various kinases are now under investigation.

\section{Experimental}

\subsection{Chemistry}

IR spectra were recorded on a Perkin Elmer 881 spectrometer. NMR spectra were performed on a Bruker AVANCE $400\left({ }^{1} \mathrm{H}: 400 \mathrm{MHz},{ }^{13} \mathrm{C}: 100 \mathrm{MHz}\right.$ ) (chemical shifts $\delta$ in $\mathrm{ppm}$, the following abbreviations are used: singlet $(\mathrm{s})$, doublet (d), triplet (t), pseudo-triplet (pt), doubled triplet (dt), multiplet $(\mathrm{m})$, br s (broad signal), tertiary carbons (C tert), quaternary carbons (C quat). The signals were assigned from ${ }^{1} \mathrm{H}-{ }^{1} \mathrm{H}$ COSY and ${ }^{13} \mathrm{C}-{ }^{1} \mathrm{H}$ correlations.
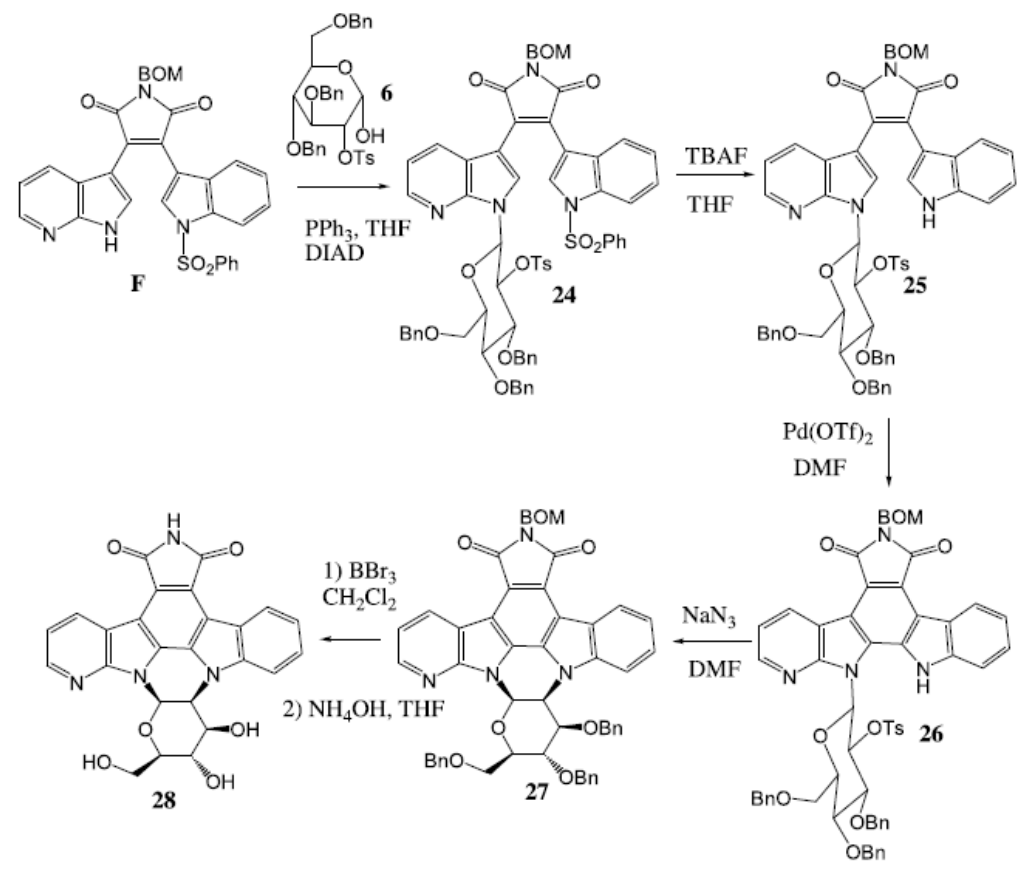

Scheme 6. Synthesis of the bridged compound 28 . 
Low-resolution mass spectra (ESI + and APCI + ) were determined on a MS Hewlett Packard engine. HRMS spectra $(\mathrm{FAB}+)$ were determined on a high resolution Fisons Autospec-Q spectrometer at CESAMO (Talence, France). Chromatographic purifications were performed by flash silicagel Geduran SI 60 (Merck) $0.040-0.063 \mathrm{~mm}$ or Kieselgel 60 (Merck) $0.063-0.200 \mathrm{~mm}$ column chromatography. For purity tests, TLC were performed on fluorescent silica gel plates $\left(60 \mathrm{~F}_{254}\right.$ from Merck).

4.1.1. 1- $O$-Acetyl-2- $O$-tosyl-3,4,6-tri- $O$-benzyl- $\alpha$ and $\beta$-Dglucopyranose 2. To a solution of $1(548 \mathrm{mg}, 1.11 \mathrm{mmol}$, $\alpha / \beta$ ratio 3:10) in pyridine $(6 \mathrm{~mL})$ and $\mathrm{CH}_{2} \mathrm{Cl}_{2}(15 \mathrm{~mL})$ was added tosyl chloride $(766 \mathrm{mg}, 5.55 \mathrm{mmol})$. After refluxing for $72 \mathrm{~h}, 2 \mathrm{~N} \mathrm{HCl}(15 \mathrm{~mL})$ was added. After extraction with EtOAc, the organic phase was washed with saturated aqueous $\mathrm{NaHCO}_{3}$ and then with brine. The organic phase was dried over $\mathrm{MgSO}_{4}$, the solvent was removed and the residue was purified by flash chromatography (eluent cyclohexane/EtOAc from 9:1 to 7:3) to give 2 as a colorless oil (603 mg, $0.93 \mathrm{mmol}, 84 \%$ yield) as a mixture of $\beta$ and $\alpha$ anomers in 8:5 ratio, respectively. Unreacted 1 ( $\beta$ anomer, $150 \mathrm{mg}$ ) was recovered.

Compound 2. IR ( $\mathrm{NaCl}$ film), $\nu_{\mathrm{C}=\mathrm{O}} 1739,1760 \mathrm{~cm}^{-1}$. HRMS $(\mathrm{FAB}+)[\mathrm{M}+\mathrm{Na}]^{+}$, calcd for $\mathrm{C}_{36} \mathrm{H}_{38} \mathrm{NaO}_{9} \mathrm{~S}_{1} 669$. 2134, found 669.2147. ${ }^{1} \mathrm{H}$ NMR (400 $\left.\mathrm{MHz}, \mathrm{CDCl}_{3}\right)$ : ${ }^{\beta}$ major anomer, ${ }^{\alpha}$ minor anomer $1.92\left(3 \mathrm{H}^{\beta}, \mathrm{s}, \mathrm{CH}_{3}\right), 2.11$ $\left(3 \mathrm{H}^{\alpha}, \mathrm{s}, \mathrm{CH}_{3}\right), 2.35\left(3 \mathrm{H}^{\beta}, \mathrm{s}, \mathrm{CH}_{3}\right), 2.39\left(3 \mathrm{H}^{\alpha}, \mathrm{s}, \mathrm{CH}_{3}\right), 3.54-$ $3.86\left(5 \mathrm{H}^{\beta}+5 \mathrm{H}^{\alpha}, \mathrm{m}\right), 4.43-4.82\left(7 \mathrm{H}^{\beta}+7 \mathrm{H}^{\alpha}, \mathrm{m}\right), 5.65\left(1 \mathrm{H}^{\beta}\right.$, d, $\left.J=8.0 \mathrm{~Hz}, \mathrm{H}_{1}\right), 6.18\left(1 \mathrm{H}^{\alpha}, \mathrm{d}, J=3.5 \mathrm{~Hz}, \mathrm{H}_{1}\right), 7.04-7.10$ $\left(2 \mathrm{H}^{\beta}+2 \mathrm{H}^{\alpha}, \mathrm{m}\right), 7.14-7.36\left(15 \mathrm{H}^{\beta}{ }_{\text {arom }}+15 \mathrm{H}^{\alpha}{ }_{\text {arom }}\right), 7.73-$ $7.79\left(2 \mathrm{H}^{\beta}+2 \mathrm{H}^{\alpha}, \mathrm{m}\right) .{ }^{13} \mathrm{C}$ NMR $\left(100 \mathrm{MHz}, \mathrm{CDCl}_{3}\right): 20.7$, 20.9, 21.6, $21.8\left(\mathrm{CH}_{3}\right), 67.7,67.8\left(\mathrm{C}_{6}\right), 73.6,73.7,75.2$, 75.4, 75.5, $75.7\left(\mathrm{CH}_{2}\right), 72.6,75.8,77.0,77.4,78.1,79.5$, 79.7, 82.4, 89.6, $91.5\left(\mathrm{C}_{1}, \mathrm{C}_{2}, \mathrm{C}_{3}, \mathrm{C}_{4}, \mathrm{C}_{5}\right), 127.6-128.6$, $129.7,130.0$ (C tert arom), 133.2, 134.7, 137.6, 137.7, $137.8,137.9,144.7,145.3$ (C quat arom), 168.6, 169.3 $(\mathrm{C}=\mathrm{O})$.

4.1.2. 1-Chloro-1-deoxy-2- $O$-tosyl-3,4,6-tri- $O$-benzyl- $\alpha$ D-glucopyranose 3 . $\mathrm{HCl}$ gas was bubbled for $20 \mathrm{~min}$ in a solution of 2 ( $444 \mathrm{mg}, 0.69 \mathrm{mmol})$ in diethylether. After stirring for $48 \mathrm{~h}$ at room temperature, the solvent was removed, the residue was dissolved in $\mathrm{CH}_{2} \mathrm{Cl}_{2}$ then the solvent was removed. The residue was purified by flash chromatography (eluent cyclohexane/EtOAc 7:3) to give $\mathbf{3}$ ( $\alpha$ anomer) as a colorless oil ( $272 \mathrm{mg}, 0.438 \mathrm{mmol}, 66 \%$ yield). Unreacted $\alpha$ anomer 2 (56 mg) was recovered. The reaction performed with pure $\beta$ anomer 2 afforded 3 in $86 \%$ yield.

Compound 3. IR ( $\mathrm{NaCl}$ film) $\nu_{\mathrm{S}=\mathrm{O}} 1739 \mathrm{~cm}^{-1}$. HRMS $(\mathrm{FAB}+)[\mathrm{M}+\mathrm{Na}]^{+}$, calcd for $\mathrm{C}_{34} \mathrm{H}_{35} \mathrm{ClNaO}_{7} \mathrm{~S} 645.1690$, found $645.1699 .{ }^{1} \mathrm{H} \mathrm{NMR}\left(400 \mathrm{MHz}, \mathrm{CDCl}_{3}\right): 2.39(3 \mathrm{H}, \mathrm{s}$, $\left.\mathrm{CH}_{3}\right), 3.66\left(1 \mathrm{H}, \mathrm{dd}, J_{1}=11.0 \mathrm{~Hz}, J_{2}=2.0 \mathrm{~Hz}\right), 3.76-3.83$ $(2 \mathrm{H}, \mathrm{m}), 4.05(1 \mathrm{H}, \mathrm{t}, J=9.5 \mathrm{~Hz}), 4.10(1 \mathrm{H}, \mathrm{m}), 4.48(1 \mathrm{H}, \mathrm{d}$, $J=10.5 \mathrm{~Hz}), 4.49(1 \mathrm{H}, \mathrm{d}, J=12.0 \mathrm{~Hz}), 4.60(1 \mathrm{H}, \mathrm{d}, J=$ $12.0 \mathrm{~Hz}), 4.61\left(1 \mathrm{H}, \mathrm{dd}, J_{1}=9.5 \mathrm{~Hz}, J_{2}=4.0 \mathrm{~Hz}\right), 4.69(1 \mathrm{H}$, $\mathrm{d}, J=11.0 \mathrm{~Hz}), 4.74(1 \mathrm{H}, \mathrm{d}, J=11.0 \mathrm{~Hz}), 4.75(1 \mathrm{H}, \mathrm{d}, J=$ $10.5 \mathrm{~Hz}), 6.21\left(1 \mathrm{H}, \mathrm{d}, J=4.0 \mathrm{~Hz}, \mathrm{H}_{1}\right), 7.08-7.11(2 \mathrm{H}, \mathrm{m})$, $7.16-7.23(4 \mathrm{H}, \mathrm{m}), 7.25-7.37\left(11 \mathrm{H}_{\text {arom }}\right), 7.80(2 \mathrm{H}, \mathrm{d}, J=$ $8.5 \mathrm{~Hz}) .{ }^{13} \mathrm{C}$ NMR $\left(100 \mathrm{MHz}, \mathrm{CDCl}_{3}\right): 21.7\left(\mathrm{CH}_{3}\right), 67.4$
$\left(\mathrm{C}_{6}\right), 73.6,75.4,75.6\left(\mathrm{CH}_{2}\right), 73.4,76.6,78.6,79.1,91.8\left(\mathrm{C}_{1}\right.$, $\left.\mathrm{C}_{2}, \mathrm{C}_{3}, \mathrm{C}_{4}, \mathrm{C}_{5}\right), 127.7,127.8-128.1,128.3,128.4,128.5$ (C tert arom), 133.0, 137.5, 137.6, 137.7, 145.3 (C quat arom).

4.1.3. 6-Methyl-5,7-dihydro-12,13-(3,4,6-tri- $O$-benzyl- $\beta$ D-mannopyranose-1,2-diyl)-pyrrolo $[3,4-c]$ pyrido $\left[2^{\prime}, 3^{\prime}\right.$ : 4,5] pyrrolo[2,3-a] carbazole-5,7-dione 4. To a solution of aglycone A $(73 \mathrm{mg}, 0.214 \mathrm{mmol})$ in acetonitrile $(8.5 \mathrm{~mL})$ were added powdered $\mathrm{KOH}(92 \mathrm{mg})$ and tris[2-(2-methoxyethoxy) ethyl]amine $(34 \mu \mathrm{L})$. After stirring at room temperature for $15 \mathrm{~min}$, a solution of $\mathbf{3}(290 \mathrm{mg}$, $0.466 \mathrm{mmol})$ in acetonitrile $(4.5 \mathrm{~mL})$ was added dropwise. The mixture was stirred at room temperature for $48 \mathrm{~h}$. After acidification with $1 \mathrm{~N} \mathrm{HCl}(10 \mathrm{~mL})$, the mixture was extracted with EtOAc. The organic phase was washed with brine, dried over $\mathrm{MgSO}_{4}$ and the solvent was removed. The residue was partly purified by flash chromatography (eluent cyclohexane/EtOAc from 9:1 to 5:5 then EtOAc $100 \%$ ) to give a mixture of glycosylated compounds $(24 \mathrm{mg})$. To the mixture of the glycosylated compounds in DMF $(1 \mathrm{~mL})$ was added $\mathrm{NaN}_{3}(32 \mathrm{mg}, 0.50 \mathrm{mmol})$. After stirring at $70^{\circ} \mathrm{C}$ for $48 \mathrm{~h}$, water was added and the mixture was extracted with EtOAc. The organic phase was dried over $\mathrm{MgSO}_{4}$, the solvent was removed and the residue was purified by flash chromatography (eluent cyclohexane/ EtOAc from 9:1 to 5:5 then EtOAc 100\%) affording 4 (20 mg, $0.026 \mathrm{mmol}, 12 \%$ yield from $\mathbf{A}$ ) as a yellow solid.

Compound 4. Mp 67-69 ${ }^{\circ} \mathrm{C}$. IR $(\mathrm{KBr}) \nu_{\mathrm{C}=\mathrm{O}} 1700 \mathrm{~cm}^{-1}$. HRMS $(\mathrm{FAB}+)[\mathrm{M}+\mathrm{H}]^{+}$, calcd for $\mathrm{C}_{47} \mathrm{H}_{39} \mathrm{~N}_{4} \mathrm{O}_{6}$ 755.2870 , found 755.2871 . The ${ }^{1} \mathrm{H}$ NMR signals were assigned from ${ }^{1} \mathrm{H}-{ }^{1} \mathrm{H}$ COSY correlations. ${ }^{1} \mathrm{H}$ NMR $\left(400 \mathrm{MHz}, \mathrm{CDCl}_{3}\right): 3.30\left(3 \mathrm{H}, \mathrm{s}, \mathrm{CH}_{3}\right), 3.79(1 \mathrm{H}, \mathrm{d}, J=$ $11.0 \mathrm{~Hz}), 3.91\left(1 \mathrm{H}, \mathrm{dd}, J_{1}=10.5 \mathrm{~Hz}, J_{2}=5.5 \mathrm{~Hz}, \mathrm{H}_{6^{\prime}}\right)$, 3.96-4.03 $\left(2 \mathrm{H}, \mathrm{m}, \mathrm{H}_{3^{\prime}}, \mathrm{H}_{6^{\prime}}\right), 4.09\left(1 \mathrm{H}, \mathrm{t}, J=9.5 \mathrm{~Hz}, \mathrm{H}_{4^{\prime}}\right)$, $4.42\left(1 \mathrm{H}, \mathrm{m}, \mathrm{H}_{5^{\prime}}\right), 4.43(1 \mathrm{H}, \mathrm{d}, J=11.0 \mathrm{~Hz}), 4.64(1 \mathrm{H}, \mathrm{d}$, $J=11.0 \mathrm{~Hz}), 4.66(1 \mathrm{H}, \mathrm{d}, J=12.0 \mathrm{~Hz}), 4.75(1 \mathrm{H}, \mathrm{d}, J=$ $11.5 \mathrm{~Hz}), 4.91(1 \mathrm{H}, \mathrm{d}, J=11.0 \mathrm{~Hz}), 5.52\left(1 \mathrm{H}, \mathrm{m}, \mathrm{H}_{2^{\prime}}\right), 6.15$ $\left(1 \mathrm{H}, \mathrm{d}, J=3.5 \mathrm{~Hz}, \mathrm{H}_{1^{\prime}}\right), 6.45(2 \mathrm{H}, \mathrm{d}, J=7.0 \mathrm{~Hz}), 6.89(2 \mathrm{H}, \mathrm{t}$, $J=7.5 \mathrm{~Hz}), 7.03(1 \mathrm{H}, \mathrm{t}, J=7.5 \mathrm{~Hz}), 7.14-7.18(2 \mathrm{H}, \mathrm{m})$, 7.24-7.30 (3H, m), 7.32-7.39 (2H, m), 7.40-7.47 (6H, m), $7.99(1 \mathrm{H}, \mathrm{m}), 8.52\left(1 \mathrm{H}, \mathrm{dd}, J_{1}=4.0 \mathrm{~Hz}, J_{2}=1.0 \mathrm{~Hz}\right), 8.82$ $(1 \mathrm{H}, \mathrm{m}), 8.95\left(1 \mathrm{H}, \mathrm{dd}, J_{1}=8.0 \mathrm{~Hz}, J_{2}=1.0 \mathrm{~Hz}\right) .{ }^{13} \mathrm{C} \mathrm{NMR}$ $\left(100 \mathrm{MHz}, \mathrm{CDCl}_{3}\right): 23.9\left(\mathrm{NCH}_{3}\right), 58.3,74.5,78.3,80.4$, $85.0\left(\mathrm{C}_{1^{\prime}}, \mathrm{C}_{2^{\prime}}, \mathrm{C}_{3^{\prime}}, \mathrm{C}_{4^{\prime}}, \mathrm{C}_{5^{\prime}}\right), 68.9\left(\mathrm{C}_{6^{\prime}}\right), 73.8,75.1,75.9$ $\left(\mathrm{CH}_{2}\right), 110.4,113.3,116.5,117.7,121.9,125.3,127.4$, $130.2,136.1,137.6,137.9,143.3,152.3$ (C quat arom), 113.6, 117.3, 122.9, 125.6, 127.7-128.7, 134.1, 146.5 (C tert arom), 170.0, $170.1(\mathrm{C}=\mathrm{O})$.

4.1.4. 6-Methyl-5,7-dihydro-12,13-( $\beta$-D-mannopyranose1,2-diyl)-pyrrolo $[3,4-c]$ pyrido $\left[2^{\prime}, 3^{\prime}: 4,5\right]$ pyrrolo $[2,3-a]$ carbazole-5,7-dione 5. To a solution of $\mathbf{4}(10 \mathrm{mg}$, $0.013 \mathrm{mmol})$ in $\mathrm{CH}_{2} \mathrm{Cl}_{2}(5 \mathrm{~mL})$ cooled to $-78^{\circ} \mathrm{C}$ was added $1 \mathrm{M} \mathrm{BBr}_{3}$ in $\mathrm{CH}_{2} \mathrm{Cl}_{2}(87 \mu \mathrm{L}, 0.08 \mathrm{mmol})$. After stirring for $10 \mathrm{~min}$ at $-78^{\circ} \mathrm{C}$, water was added, the mixture was allowed to reach room temperature then it was extracted with EtOAc. The organic phase was dried over $\mathrm{MgSO}_{4}$, the solvent was removed and the residue was purified by flash chromatography (eluent from EtOAc 100\% to EtOAc/ $\mathrm{MeOH} 9: 1)$ to give $5(5.6 \mathrm{mg}, 0.012 \mathrm{mmol}, 90 \%$ yield $)$ as a yellow solid. 
Compound 5. Mp $245-250{ }^{\circ} \mathrm{C}$ (decomposition). IR ( $\mathrm{KBr}$ ) $\nu_{\mathrm{C}=\mathrm{O}} 1700 \mathrm{~cm}^{-1}, \nu_{\mathrm{OH}} 3040-3680 \mathrm{~cm}^{-1}$. HRMS (FAB + ) $[\mathrm{M}+\mathrm{H}]^{+}$, calcd for $\mathrm{C}_{26} \mathrm{H}_{21} \mathrm{~N}_{4} \mathrm{O}_{6}$ 485.1461, found 485.1465. ${ }^{1} \mathrm{H}$ NMR (400 MHz, DMSO- $\left.d_{6}\right): 3.19(3 \mathrm{H}, \mathrm{s}$, $\left.\mathrm{NCH}_{3}\right), 3.59-3.66(2 \mathrm{H}, \mathrm{m}), 3.79(1 \mathrm{H}, \mathrm{m}), 3.97(1 \mathrm{H}, \mathrm{m}), 4.06$ $(1 \mathrm{H}, \mathrm{m}), 5.18-5.28\left(3 \mathrm{H}, \mathrm{m}, 2 \mathrm{OH}, \mathrm{H}_{2^{\prime}}\right), 5.40(1 \mathrm{H}, \mathrm{d}, J=$ $5.5 \mathrm{~Hz}, \mathrm{OH}), 6.42\left(1 \mathrm{H}, \mathrm{d}, J=4.0 \mathrm{~Hz}, \mathrm{H}_{1^{\prime}}\right), 7.49(1 \mathrm{H}$, dd, $\left.J_{1}=8.0 \mathrm{~Hz}, J_{2}=5.0 \mathrm{~Hz}\right), 7.51(1 \mathrm{H}, \mathrm{t}, J=7.5 \mathrm{~Hz}), 7.64(1 \mathrm{H}$, $\left.\mathrm{dt}, J_{1}=7.5 \mathrm{~Hz}, J_{2}=1.0 \mathrm{~Hz}\right), 8.24(1 \mathrm{H}, \mathrm{d}, J=8.0 \mathrm{~Hz}), 8.63$ $\left(1 \mathrm{H}, \mathrm{dd}, J_{1}=5.0 \mathrm{~Hz}, J_{2}=1.5 \mathrm{~Hz}\right), 8.72(1 \mathrm{H}, \mathrm{d}, J=7.5 \mathrm{~Hz})$, $8.89\left(1 \mathrm{H}, \quad \mathrm{dd}, \quad J_{1}=8.0 \mathrm{~Hz}, J_{2}=1.5 \mathrm{~Hz}\right) .{ }^{13} \mathrm{C} \quad \mathrm{NMR}$ $\left(100 \mathrm{MHz}\right.$, DMSO- $\left.d_{6}\right): 23.6\left(\mathrm{CH}_{3}\right), 61.1\left(\mathrm{C}_{6^{\prime}}\right), 59.2\left(\mathrm{C}_{2^{\prime}}\right)$, $70.1,73.6,76.8\left(\mathrm{C}_{3^{\prime}}, \mathrm{C}_{4^{\prime}}, \mathrm{C}_{5^{\prime}}\right), 84.6\left(\mathrm{C}_{1^{\prime}}\right), 109.2,114.6$, $116.1,120.1,120.9,124.4,127.6,130.2,143.0,152.8(\mathrm{C}$ quat arom), 114.1, 116.9, 122.1, 124.2, 127.7, 132.1, 146.9 $(\mathrm{C}$ tert arom $), 169.5,169.6(\mathrm{C}=\mathrm{O})$.

4.1.5. 2-Benzyloxymethyl-5,7-dihydro- $12 H, 13 H$-pyrrolo $[3,4-c]$ pyrido $\left[2^{\prime}, 3^{\prime}: 4,5\right]$ pyrrolo $[2,3-a]$ carbazole-5,7dione D. To a solution of aglycone $\mathbf{C}(218 \mathrm{mg}, 0.486 \mathrm{mmol})$ in benzene $(300 \mathrm{~mL})$ was added iodine $(1.32 \mathrm{~g}, 5.32 \mathrm{mmol})$. The mixture was irradiated for $7 \mathrm{~h}$ with a medium pressure mercury lamp $(400 \mathrm{~W})$. The solvent was removed, and the residue dissolved in EtOAc $(250 \mathrm{~mL})$ and washed with saturated aqueous sodium thiosulfate $(100 \mathrm{~mL})$ and then with brine. The organic phase was dried over $\mathrm{MgSO}_{4}$, the solvent was removed and the residue was purified by flash chromatography (eluent EtOAc/cyclohexane 5:5) to give D (120 mg, $0.267 \mathrm{mmol}, 55 \%$ yield) as a yellow solid.

Compound D. Mp $>290{ }^{\circ} \mathrm{C}$ (degradation). IR $(\mathrm{KBr}) \nu_{\mathrm{C}=\mathrm{O}}$ $1700,1750 \mathrm{~cm}^{-1}, \nu_{\mathrm{NH}} 3000-3600 \mathrm{~cm}^{-1}$. Mass (ESI+) $[\mathrm{M}+\mathrm{H}]^{+}$447. ${ }^{1} \mathrm{H}$ NMR $\left(400 \mathrm{MHz}\right.$, DMSO- $\left.d_{6}\right): 4.67(2 \mathrm{H}$, $\left.\mathrm{s}, \mathrm{CH}_{2}\right), 5.08\left(2 \mathrm{H}, \mathrm{s}, \mathrm{CH}_{2}\right), 7.24-7.43(7 \mathrm{H}, \mathrm{m}), 7.57(1 \mathrm{H}, \mathrm{t}$, $J=7.5 \mathrm{~Hz}), 7.78(1 \mathrm{H}, \mathrm{d}, J=8.0 \mathrm{~Hz}), 8.55(1 \mathrm{H}, \mathrm{d}, J=$ $3.5 \mathrm{~Hz}), 8.90(1 \mathrm{H}, \mathrm{d}, J=8.0 \mathrm{~Hz}), 9.05(1 \mathrm{H}, \mathrm{d}, J=7.5 \mathrm{~Hz})$, $11.45(1 \mathrm{H}, \mathrm{s}, \mathrm{NH}), 12.08(1 \mathrm{H}, \mathrm{s}, \mathrm{NH}) .{ }^{13} \mathrm{C} \mathrm{NMR}(100 \mathrm{MHz}$, $\left.\mathrm{CDCl}_{3}\right)$ : 66.4, $70.3\left(\mathrm{CH}_{2}\right), 112.1,116.6,120.4,124.1,127.1$, 127.4, 127.5 (2C), $128.2(2 \mathrm{C}), 132.1,147.3$ (C tert arom), $113.0,114.1,116.1,118.5,118.8,121.1,127.8,128.8$, $137.8,140.2,151.8$ (C quat arom), 168.9, $169.0(\mathrm{C}=\mathrm{O})$.

4.1.6. 2-O-Tosyl-3,4,6-tri- $O$-benzyl- $\alpha$-D-glucopyranose 6 . To a solution of $2(300 \mathrm{mg}, 0.462 \mathrm{mmol}$, anomeric ratio $\alpha / \beta$ $5: 8)$ in $\mathrm{THF} / \mathrm{MeOH}(5 \mathrm{~mL}, 1: 1 \mathrm{v} / \mathrm{v})$ at $0{ }^{\circ} \mathrm{C}$ was added dropwise $1 \mathrm{M} \mathrm{NaOMe} / \mathrm{MeOH}(60 \mu \mathrm{L})$. The mixture was stirred at $0{ }^{\circ} \mathrm{C}$ for $1 \mathrm{~h}$, the solvent was removed and the residue purified by flash chromatography (eluent cyclohexane/EtOAc 7:3) affording 6 (204 mg, $0.038 \mathrm{mmol}, 73 \%$ yield) as a white solid.

Compound 6. $\mathrm{Mp} 118-120^{\circ} \mathrm{C}$. IR (KBr) $\nu_{\mathrm{OH}} 3240$ $3600 \mathrm{~cm}^{-1}$. Mass $(\mathrm{ESI}+)[\mathrm{M}+\mathrm{H}]^{+} 604,[\mathrm{M}+\mathrm{Na}]^{+} 627$. ${ }^{1} \mathrm{H}$ NMR $\left(400 \mathrm{MHz}, \mathrm{CDCl}_{3}\right): 2.17\left(3 \mathrm{H}, \mathrm{s}, \mathrm{CH}_{3}\right), 3.35-3.50$ $(4 \mathrm{H}, \mathrm{m}), 3.80-3.90(2 \mathrm{H}, \mathrm{m}), 4.23(1 \mathrm{H}, \mathrm{d}, J=10.0 \mathrm{~Hz}), 4.24$ $(1 \mathrm{H}, \mathrm{d}, J=11.5 \mathrm{~Hz}), 4.30(1 \mathrm{H}, \mathrm{d}, J=12.0 \mathrm{~Hz}), 4.39(1 \mathrm{H}, \mathrm{d}$, $J=11.5 \mathrm{~Hz}), 4.48(2 \mathrm{H}, \mathrm{s}), 4.53(1 \mathrm{H}, \mathrm{d}, J=11.0 \mathrm{~Hz}), 5.24$ $\left(1 \mathrm{H}\right.$, br s, $\left.\mathrm{H}_{1}\right), 6.85-6.89(2 \mathrm{H}, \mathrm{m}), 6.94-6.98(4 \mathrm{H}, \mathrm{m}), 7.04-$ $7.16\left(11 \mathrm{H}_{\text {arom }}\right), 7.58(2 \mathrm{H}, \mathrm{d}, J=8.0 \mathrm{~Hz}) .{ }^{13} \mathrm{C} \mathrm{NMR}$ $\left(100 \mathrm{MHz}, \mathrm{CDCl}_{3}\right): 21.7\left(\mathrm{CH}_{3}\right), 68.3\left(\mathrm{C}_{6}\right), 73.5,75.1$, $75.2\left(\mathrm{CH}_{2}\right), 70.0,77.9,79.0,80.0,90.9\left(\mathrm{C}_{1}, \mathrm{C}_{2}, \mathrm{C}_{3}, \mathrm{C}_{4}, \mathrm{C}_{5}\right)$, 127.5-128.5, 129.6, 129.8 (C tert arom), 133.3, 137.6, $137.8,138.0,144.9$ (C quat arom).
4.1.7. 1-Benzyloxymethyl-2,5-dihydro-3-[1-(2-O-tosyl3,4,6-tri- $O$-benzyl- $\beta$-D-glucopyranos-1-yl)-indol-3-yl]-4[1-phenylsulfonyl-pyrrolo[2,3-b]pyridin-3-yl]-pyrrole2,5-dione 7. To a solution of $\mathbf{B}(89 \mathrm{mg}, 0.152 \mathrm{mmol})$ in THF $(8 \mathrm{~mL})$ were added $\mathbf{6}(205 \mathrm{mg}, 0.338 \mathrm{mmol})$ and triphenylphosphine ( $89 \mathrm{mg}, 0.338 \mathrm{mmol})$. The mixture was cooled to $-78^{\circ} \mathrm{C}$ then diisopropyl azodicarboxylate (DIAD) $(65.5 \mu \mathrm{M}, 0.338 \mathrm{mmol})$ was added dropwise. The mixture was allowed to reach room temperature then was stirred for $18 \mathrm{~h}$. Water was added. After extraction with EtOAc, the organic phase was dried over $\mathrm{MgSO}_{4}$, the solvent was removed and the residue was purified by flash chromatography (eluent cyclohexane/EtOAc 8:2) to give 7 (156 mg, $0.133 \mathrm{mmol}, 88 \%$ yield) as a red solid.

Compound 7. Mp $47-50{ }^{\circ} \mathrm{C}$. IR (KBr) $\nu_{\mathrm{C}=\mathrm{O}} 1710$, $1770 \mathrm{~cm}^{-1}$. Mass (ESI+) $[\mathrm{M}+\mathrm{H}]^{+} 1175 .{ }^{1} \mathrm{H}$ NMR $\left(400 \mathrm{MHz}, \mathrm{CDCl}_{3}\right): 1.93\left(3 \mathrm{H}, \mathrm{s}, \mathrm{CH}_{3}\right), 3.53-3.59(2 \mathrm{H}, \mathrm{m})$, $3.63\left(1 \mathrm{H}, \mathrm{dd}, J_{1}=9.0 \mathrm{~Hz}, J_{2}=3.5 \mathrm{~Hz}\right), 3.70(1 \mathrm{H}, \mathrm{t}, J=$ $9.0 \mathrm{~Hz}), 3.84(1 \mathrm{H}, \mathrm{t}, J=9.5 \mathrm{~Hz}), 4.34(1 \mathrm{H}, \mathrm{d}, J=12.0 \mathrm{~Hz})$, $4.42(1 \mathrm{H}, \mathrm{d}, J=12.0 \mathrm{~Hz}), 4.43-4.47(2 \mathrm{H}, \mathrm{m}), 4.57(2 \mathrm{H}, \mathrm{s})$, $4.58(1 \mathrm{H}, \mathrm{d}, J=8.5 \mathrm{~Hz}), 4.62(1 \mathrm{H}, \mathrm{d}, J=10.5 \mathrm{~Hz}), 5.03(1 \mathrm{H}$, $\mathrm{d}, J=9.0 \mathrm{~Hz}), 5.07(2 \mathrm{H}, \mathrm{s}), 5.34\left(1 \mathrm{H}, \mathrm{d}, J=9.0 \mathrm{~Hz}, \mathrm{H}_{1^{\prime}}\right)$, $6.19-6.28(2 \mathrm{H}, \mathrm{m}), 6.56(2 \mathrm{H}, \mathrm{d}, J=8.0 \mathrm{~Hz}), 6.62(1 \mathrm{H}, \mathrm{dd}$, $\left.J_{1}=8.0 \mathrm{~Hz}, J_{2}=3.5 \mathrm{~Hz}\right), 6.82(1 \mathrm{H}, \mathrm{t}, J=8.0 \mathrm{~Hz}), 6.91-6.97$ $(2 \mathrm{H}, \mathrm{m}), 7.02-7.19\left(20 \mathrm{H}_{\text {arom }}\right), 7.23(2 \mathrm{H}, \mathrm{d}, J=8.0 \mathrm{~Hz}), 7.31$ $(2 \mathrm{H}, \mathrm{t}, J=7.5 \mathrm{~Hz}), 7.43\left(1 \mathrm{H}, \mathrm{dt}, J_{1}=8.0 \mathrm{~Hz}, J_{2}=1.0 \mathrm{~Hz}\right)$, $7.90(1 \mathrm{H}, \mathrm{s}), 7.96(2 \mathrm{H}, \mathrm{d}, J=8.0 \mathrm{~Hz}), 7.98(1 \mathrm{H}, \mathrm{s}), 8.07(1 \mathrm{H}$, $\mathrm{d}, J=5.0 \mathrm{~Hz}) .{ }^{13} \mathrm{C}$ NMR $\left(100 \mathrm{MHz}, \mathrm{CDCl}_{3}\right): 22.0\left(\mathrm{CH}_{3}\right)$, 67.4, $68.0\left(\mathrm{CH}_{2}\right), 71.8,73.5,75.2,75.4\left(\mathrm{C}_{6^{\prime}}+\mathrm{CH}_{2}\right), 70.1$, 77.5, 78.2, 79.9, 83.0 $\left(\mathrm{C}_{1^{\prime}}, \mathrm{C}_{2^{\prime}}, \mathrm{C}_{3^{\prime}}, \mathrm{C}_{4^{\prime}}, \mathrm{C}_{5^{\prime}}\right), 119.3,121.4$, $121.5,123.0,127.2,127.5-128.5,129.1,129.3,131.4$, 134.1, 145.4 (C tert arom), 106.5, 109.5, 123.6, 126.0, $131.1,133.3,135.6,137.5,137.6,137.7,137.8,138.0$, 144.3, 146.6 (C quat arom), $170.7(2 \mathrm{C}=\mathrm{O})$.

4.1.8. 1-Benzyloxymethyl-2,5-dihydro-3-[1-(2-O-tosyl3,4,6- $O$-benzyl- $\beta$-D-glucopyranos-1-yl)-indol-3-yl]-4[1H-pyrrolo[2,3-b]pyridin-3-yl]-pyrrole-2,5-dione 8. To a solution of 7 (160 $\mathrm{mg}, 0.136 \mathrm{mmol})$ in THF $(5 \mathrm{~mL})$ was added a $1.1 \mathrm{M}$ solution of tetrabutylammonium fluoride in THF $(409 \mu \mathrm{L}, 0.448 \mathrm{mmol})$. The mixture was stirred for $2.5 \mathrm{~h}$ at room temperature. Water was added. After extraction with EtOAc, the organic phase was dried over $\mathrm{MgSO}_{4}$, the solvent was removed and the residue was purified by flash chromatography (eluent cyclohexane/ EtOAc 3:2) to give 8 (114 mg, $0.110 \mathrm{mmol}, 81 \%$ yield) as a red solid.

Compound 8. Mp $75-80{ }^{\circ} \mathrm{C}$. IR (KBr) $\nu_{\mathrm{C}=\mathrm{O}} 1765$, $1710 \mathrm{~cm}^{-1}, \nu_{\mathrm{NH}} 3240-3600 \mathrm{~cm}^{-1}$. Mass (ESI+) [M+ $\mathrm{H}]^{+}$1035. ${ }^{1} \mathrm{H}$ NMR $\left(400 \mathrm{MHz}, \mathrm{CDCl}_{3}\right): 2.12\left(3 \mathrm{H}, \mathrm{s}, \mathrm{CH}_{3}\right)$, $3.72-3.86(3 \mathrm{H}, \mathrm{m}), 3.94(1 \mathrm{H}, \mathrm{t}, J=9.0 \mathrm{~Hz}), 4.04(1 \mathrm{H}, \mathrm{t}, J=$ $9.0 \mathrm{~Hz}), 4.53(1 \mathrm{H}, \mathrm{d}, J=12.0 \mathrm{~Hz}), 4.60(1 \mathrm{H}, \mathrm{d}, J=12.0 \mathrm{~Hz})$, $4.67(1 \mathrm{H}, \mathrm{d}, J=11.0 \mathrm{~Hz}), 4.80(4 \mathrm{H}, \mathrm{s}+\mathrm{m}), 4.85(1 \mathrm{H}, \mathrm{d}, J=$ $10.5 \mathrm{~Hz}), 5.30(3 \mathrm{H}, \mathrm{s}+\mathrm{m}), 5.56\left(1 \mathrm{H}, \mathrm{d}, J=9.0 \mathrm{~Hz}, \mathrm{H}_{1^{\prime}}\right)$, 6.69-6.78 (5H, m), $7.02(1 \mathrm{H}, \mathrm{m}), 7.15-7.21(2 \mathrm{H}, \mathrm{m}), 7.26-$ $7.40(19 \mathrm{H}), 7.47(2 \mathrm{H}, \mathrm{d}, J=7.5 \mathrm{~Hz}), 7.55(1 \mathrm{H}, \mathrm{t}, J=$ $8.0 \mathrm{~Hz}), 8.00(2 \mathrm{H}, \mathrm{d}, J=9.5 \mathrm{~Hz}), 8.14(1 \mathrm{H}, \mathrm{d}, J=4.5 \mathrm{~Hz})$, $12.4(1 \mathrm{H}, \mathrm{s}, \mathrm{NH}) .{ }^{13} \mathrm{C} \mathrm{NMR}\left(100 \mathrm{MHz}, \mathrm{CDCl}_{3}\right): 21.5\left(\mathrm{CH}_{3}\right)$, 67.2, 68.2 $\left(\mathrm{CH}_{2}\right), 71.7,73.5,75.3,75.4\left(\mathrm{C}_{6^{\prime}}+\mathrm{CH}_{2}\right), 77.6$, 78.2, 80.1, 83.1 $\left(\mathrm{C}_{1^{\prime}}, \mathrm{C}_{2^{\prime}}, \mathrm{C}_{3^{\prime}}, \mathrm{C}_{4^{\prime}}, \mathrm{C}_{5^{\prime}}\right), 116.7,120.9,122.1$, 122.8, 127.0, 127.5-128.5, 129.1, 129.8, 131.4, 142.8 (C tert 
arom), 105.3, 107.4, 119.0, 126.4, 126.9, 133.2, 135.6, 137.5-137.9, 144.2, 148.6 (C quat arom), 171.3, 171.7 $(\mathrm{C}=\mathrm{O})$.

4.1.9. 6-Benzyloxymethyl-12-(3,4,6-tri- $O$-benzyl-2- $O$ tosyl- $\beta$-D-glucopyranos-1-yl)-5,7-dihydro- $13 H$-pyrido$\left[3^{\prime}, 2^{\prime}: 4,5\right]$ pyrrolo $[2,3-a]$ pyrrolo $[3,4-c]$ carbazole-5,7dione 9 . To a solution of $\mathbf{8}(50 \mathrm{mg}, 0.048 \mathrm{mmol})$ in benzene $(150 \mathrm{~mL})$ was added iodine $(18 \mathrm{mg}, 0.071 \mathrm{mmol})$. The mixture was irradiated for $1.5 \mathrm{~h}$ with a medium pressure mercury lamp $(400 \mathrm{~W})$. The solvent was removed, and the residue was dissolved in EtOAc $(250 \mathrm{~mL})$ and washed with saturated aqueous sodium thiosulfate $(50 \mathrm{~mL})$ and then with brine. The organic phase was dried over $\mathrm{MgSO}_{4}$, the solvent was removed and the residue was purified by flash chromatography (eluent EtOAc/cyclohexane 3:7) to give 9 (31 mg, $0.030 \mathrm{mmol}, 62 \%$ yield) as a yellow solid.

Compound 9. $\mathrm{Mp} 37-40{ }^{\circ} \mathrm{C}$. IR $(\mathrm{KBr}) \nu_{\mathrm{C}=\mathrm{O}} 1710$, $1755 \mathrm{~cm}^{-1}, \nu_{\mathrm{NH}} 3200-3600 \mathrm{~cm}^{-1}$. Mass $(\mathrm{ESI}+)[\mathrm{M}+$ $\mathrm{H}]^{+}$1033. ${ }^{1} \mathrm{H}$ NMR $\left(400 \mathrm{MHz}, \mathrm{CDCl}_{3}\right): 2.10\left(3 \mathrm{H}, \mathrm{s}, \mathrm{CH}_{3}\right)$, $3.65\left(1 \mathrm{H}, \mathrm{dd}, J_{1}=10.0 \mathrm{~Hz}, J_{2}=2.5 \mathrm{~Hz}\right), 3.81(1 \mathrm{H}, \mathrm{d}, J=$ $10.0 \mathrm{~Hz}), 3.93(1 \mathrm{H}, \mathrm{d}, J=10.0 \mathrm{~Hz}), 3.99(1 \mathrm{H}, \mathrm{t}, J=9.0 \mathrm{~Hz})$, $4.17(1 \mathrm{H}, \mathrm{d}, J=10.5 \mathrm{~Hz}), 4.44(1 \mathrm{H}, \mathrm{d}, J=10.0 \mathrm{~Hz}), 4.47$ $(1 \mathrm{H}, \mathrm{d}, J=9.0 \mathrm{~Hz}), 4.70(1 \mathrm{H}, \mathrm{d}, J=10.5 \mathrm{~Hz}), 4.74(2 \mathrm{H}, \mathrm{s})$, $4.76(1 \mathrm{H}, \mathrm{d}, J=11.5 \mathrm{~Hz}), 5.00(1 \mathrm{H}, \mathrm{d}, J=10.5 \mathrm{~Hz}), 5.03$ $(1 \mathrm{H}, \mathrm{d}, J=13.5 \mathrm{~Hz}), 5.15(1 \mathrm{H}, \mathrm{t}, J=9.0 \mathrm{~Hz}), 5.30(2 \mathrm{H}, \mathrm{s})$, $5.99\left(1 \mathrm{H}, \mathrm{d}, J=9.0 \mathrm{~Hz}, \mathrm{H}_{1^{\prime}}\right), 6.37(2 \mathrm{H}, \mathrm{d}, J=8.0 \mathrm{~Hz}), 6.46$ $(2 \mathrm{H}, \mathrm{d}, J=8.0 \mathrm{~Hz}), 6.74(2 \mathrm{H}, \mathrm{d}, J=7.5 \mathrm{~Hz}), 6.76-6.83(2 \mathrm{H}$, $\mathrm{m}), 6.90(1 \mathrm{H}, \mathrm{m}), 6.95-7.00(3 \mathrm{H}, \mathrm{m}), 7.10-7.45(14 \mathrm{H}), 7.50$ $\left(2 \mathrm{H}, \mathrm{dd}, J_{1}=7.5 \mathrm{~Hz}, J_{2}=0.5 \mathrm{~Hz}\right), 8.56\left(1 \mathrm{H}, \mathrm{dd}, J_{1}=5.0 \mathrm{~Hz}\right.$, $\left.J_{2}=1.5 \mathrm{~Hz}\right), 9.02(1 \mathrm{H}, \mathrm{d}, J=8.0 \mathrm{~Hz}), 9.43\left(1 \mathrm{H}, \mathrm{dd}, J_{1}=\right.$ $\left.8.0 \mathrm{~Hz}, J_{2}=1.5 \mathrm{~Hz}\right), 11.10(1 \mathrm{H}, \mathrm{s}, \mathrm{NH}) .{ }^{13} \mathrm{C}$ NMR $\left(100 \mathrm{MHz}, \mathrm{CDCl}_{3}\right): 21.5\left(\mathrm{CH}_{3}\right), 65.2,66.9\left(\mathrm{CH}_{2}\right), 71.6$, 73.2, 75.3, $76.2\left(\mathrm{C}_{6^{\prime}}+\mathrm{CH}_{2}\right), 76.3,78.4,79.7,82.3,83.4$ $\left(\mathrm{C}_{1^{\prime}}, \mathrm{C}_{2^{\prime}}, \mathrm{C}_{3^{\prime}}, \mathrm{C}_{4^{\prime}}, \mathrm{C}_{5^{\prime}}\right), 109.4,115.3,115.7,115.8,117.5$, $120.5,120.8,121.5,125.9,126.0,126.6,126.7,127.2$, 127.3, 127.6, 127.8-129.3, 129.7, 130.3, 133.8, 148.3 (C tert arom), $119.3,120.5,120.8,121.9,132.2,137.2,137.3$, 137.6 (2C), 140.7, 144.3, 153.5 (C quat arom), 169.4 (2C, $\mathrm{C}=\mathrm{O})$.

4.1.10. 6-Benzyloxymethyl-5,7-dihydro-12,13-(3,4,6-tri$O$-benzyl- $\beta$-D-mannopyranose-1,2-diyl)-pyrrolo[3,4- $c]$ pyrido $\left[2^{\prime}, 3^{\prime}: 4,5\right]$ pyrrolo $[2,3-a]$ carbazole-5,7-dione 10 . To a solution of $9(60 \mathrm{mg}, 0.06 \mathrm{mmol})$ in DMF $(2 \mathrm{~mL})$ was added $\mathrm{NaN}_{3}(37 \mathrm{mg}, 0.60 \mathrm{mmol})$. The mixture was stirred for $48 \mathrm{~h}$ at $70^{\circ} \mathrm{C}$, then water was added. After extraction with EtOAc, the organic phase was dried over $\mathrm{MgSO}_{4}$, the solvent was removed and the residue was purified by flash chromatography (eluent cyclohexane/ EtOAc 4:1) to give 10 (37 mg, $0.043 \mathrm{mmol}, 72 \%$ yield) as a yellow solid.

Compound 10. Mp 38-40 ${ }^{\circ} \mathrm{C}$. IR $(\mathrm{KBr}) \nu_{\mathrm{C}=\mathrm{O}} 1700$, $1750 \mathrm{~cm}^{-1}$. Mass (ESI+) $[\mathrm{M}+\mathrm{H}]^{+} 861 .{ }^{1} \mathrm{H}$ NMR $\left(400 \mathrm{MHz}, \mathrm{CDCl}_{3}\right): 3.60\left(1 \mathrm{H}, \mathrm{dd}, J_{1}=10.0 \mathrm{~Hz}, J_{2}=\right.$ $4.5 \mathrm{~Hz}), 3.63(1 \mathrm{H}, \mathrm{d}, J=11.5 \mathrm{~Hz}), 3.70(1 \mathrm{H}, \mathrm{d}, J=$ $12.0 \mathrm{~Hz}), 3.71(1 \mathrm{H}, \mathrm{m}), 3.76(1 \mathrm{H}, \mathrm{m}), 4.23(1 \mathrm{H}, \mathrm{d}, J=$ $12.0 \mathrm{~Hz}), 4.31(1 \mathrm{H}, \mathrm{d}, J=11.5 \mathrm{~Hz}), 4.32(1 \mathrm{H}, \mathrm{m}), 4.49(1 \mathrm{H}$, d, $J=12.0 \mathrm{~Hz}), 4.57(1 \mathrm{H}, \mathrm{m}), 4.58(1 \mathrm{H}, \mathrm{d}, J=12.0 \mathrm{~Hz}), 4.68$ $(2 \mathrm{H}, \mathrm{s}), 5.16(2 \mathrm{H}, \mathrm{AB}$ system, $J=11.0 \mathrm{~Hz}, \Delta \nu=13.0 \mathrm{~Hz})$, $5.56\left(1 \mathrm{H}, \mathrm{dd}, J_{1}=5.5 \mathrm{~Hz}, J_{2}=3.5 \mathrm{~Hz}, \mathrm{H}_{2^{\prime}}\right), 6.18(2 \mathrm{H}, \mathrm{t}, J=$
$8.0 \mathrm{~Hz}), 6.20\left(1 \mathrm{H}, \mathrm{d}, J=6.0 \mathrm{~Hz}, \mathrm{H}_{1^{\prime}}\right), 6.71(2 \mathrm{H}, \mathrm{t}, J=$ $7.5 \mathrm{~Hz}), 6.86(1 \mathrm{H}, \mathrm{t}, J=7.5 \mathrm{~Hz}), 7.10-7.38(17 \mathrm{H}, \mathrm{m}), 7.42$ $\left(1 \mathrm{H}, \mathrm{dt}, J_{1}=7.5 \mathrm{~Hz}, J_{2}=1.0 \mathrm{~Hz}\right), 7.85(1 \mathrm{H}, \mathrm{d}, J=8.0 \mathrm{~Hz})$, $8.36\left(1 \mathrm{H}, \mathrm{dd}, J_{1}=5.0 \mathrm{~Hz}, J_{2}=1.5 \mathrm{~Hz}\right), 8.71(1 \mathrm{H}, \mathrm{d}, J=$ $7.5 \mathrm{~Hz}), 8.84\left(1 \mathrm{H}, \mathrm{dd}, J_{1}=7.5 \mathrm{~Hz}, J_{2}=1.5 \mathrm{~Hz}\right) .{ }^{13} \mathrm{C} \mathrm{NMR}$ $\left(100 \mathrm{MHz}, \mathrm{CDCl}_{3}\right): 52.6,72.8,72.9,75.4,80.7\left(\mathrm{C}_{1^{\prime}}, \mathrm{C}_{2^{\prime}}\right.$, $\left.\mathrm{C}_{3^{\prime}}, \mathrm{C}_{4^{\prime}}, \mathrm{C}_{5^{\prime}}\right), 66.7\left(\mathrm{C}_{6^{\prime}}\right), 70.2,71.5,71.8,72.3,73.2\left(\mathrm{CH}_{2}\right)$, $109.3,114.2,117.5,120.2,120.4,124.6,128.8,129.0$, $136.1,137.4,137.8,138.0,142.5,151.7$ (C quat arom), $113.4,117.3,122.3,125.3,127.4,127.6-128.7,133.4,146.6$ $(\mathrm{C}$ tert arom $), 169.6(2 \mathrm{C}=\mathrm{O})$.

4.1.11. 6-Hydroxymethyl-5,7-dihydro-12,13-( $\beta$-D-mannopyranose-1,2-diyl)-pyrrolo $[3,4-c]$ pyrido $\left[2^{\prime}, 3^{\prime}: 4,5\right]$ pyrrolo[2,3-a $]$ carbazole-5,7-dione 11 . To a suspension of $10(50 \mathrm{mg}, 0.058 \mathrm{mmol})$ in EtOH/EtOAc $(5 \mathrm{~mL}, 4: 1 \mathrm{v} / \mathrm{v})$ was added $\mathrm{Pd}(\mathrm{OH})_{2} / \mathrm{C}(20 \%)(50 \mathrm{mg})$. The mixture was hydrogenated under pressure $(40 \mathrm{psi})$ at room temperature for 3 days. After filtration over Celite, the filtrate was evaporated. The residue was purified by flash chromatography (eluent $\mathrm{CH}_{2} \mathrm{Cl}_{2} / \mathrm{MeOH} 95: 5$ ) to give 11 (15 mg, $0.030 \mathrm{mmol}, 52 \%$ yield) as a yellow solid. $16 \mathrm{mg}$ of a mixture of partially debenzylated compounds could be recovered and recycled.

Compound 11. $\mathrm{Mp}>200{ }^{\circ} \mathrm{C}$ (decomposition). IR (KBr) $\nu_{\mathrm{C}=\mathrm{O}} 1700,1750 \mathrm{~cm}^{-1 ;} \nu_{\mathrm{OH}} 3100-3600 \mathrm{~cm}^{-1}$. HRMS $(\mathrm{FAB}+)[\mathrm{M}+\mathrm{H}]^{+}$, calcd for $\mathrm{C}_{26} \mathrm{H}_{20} \mathrm{~N}_{4} \mathrm{O}_{7} 501.1410$, found 501.1416. ${ }^{1} \mathrm{H}$ NMR $\left(400 \mathrm{MHz}, \mathrm{DMSO}-d_{6}\right): 3.33(1 \mathrm{H}, \mathrm{m}$, $\left.\mathrm{H}_{6^{\prime}}\right), 3.47-3.61\left(2 \mathrm{H}, \mathrm{m}, \mathrm{H}_{4^{\prime}}+\mathrm{H}_{6^{\prime}}\right), 3.70\left(1 \mathrm{H}, \mathrm{m}, \mathrm{H}_{5^{\prime}}\right), 4.30$ $\left(1 \mathrm{H}, \mathrm{m}, \mathrm{H}_{3^{\prime}}\right), 4.35\left(1 \mathrm{H}, \mathrm{t}, J=5.5 \mathrm{~Hz}, \mathrm{OH}_{6^{\prime}}\right), 5.10(2 \mathrm{H}, \mathrm{d}, J=$ $\left.6.5 \mathrm{~Hz}, \mathrm{CH}_{2} \mathrm{OH}\right), 5.35\left(1 \mathrm{H}, \mathrm{d}, J=2.5 \mathrm{~Hz}, \mathrm{H}_{2}\right), 5.48(1 \mathrm{H}, \mathrm{d}$, $\left.J=5.0 \mathrm{~Hz}, \mathrm{OH}_{4^{\prime}}\right), 6.46\left(1 \mathrm{H}, \mathrm{t}, J=7.0 \mathrm{~Hz}, \mathrm{CH}_{2} \mathrm{OH}\right), 6.97$ $\left(1 \mathrm{H}, \mathrm{s}, \mathrm{H}_{1^{\prime}}\right), 7.55(1 \mathrm{H}, \mathrm{t}, J=8.0 \mathrm{~Hz}), 7.66\left(1 \mathrm{H}, \mathrm{dd}, J_{1}=\right.$ $\left.8.0 \mathrm{~Hz}, J_{2}=5.0 \mathrm{~Hz}\right), 7.74\left(1 \mathrm{H}, \mathrm{dt}, J_{1}=8.0 \mathrm{~Hz}, J_{2}=1.0 \mathrm{~Hz}\right)$, $8.04(1 \mathrm{H}, \mathrm{d}, J=8.0 \mathrm{~Hz}), 8.20\left(1 \mathrm{H}, \mathrm{d}, J=12.5 \mathrm{~Hz}, \mathrm{OH}_{3^{\prime}}\right)$, $8.68\left(1 \mathrm{H}, \mathrm{dd}, J_{1}=5.0 \mathrm{~Hz}, J_{2}=1.5 \mathrm{~Hz}\right), 8.71(1 \mathrm{H}, \mathrm{d}, J=$ $7.5 \mathrm{~Hz}), 9.06\left(1 \mathrm{H}, \mathrm{dd}, J_{1}=7.5 \mathrm{~Hz}, J_{2}=1.5 \mathrm{~Hz}\right) .{ }^{13} \mathrm{C} \mathrm{NMR}$ $\left(100 \mathrm{MHz}\right.$, DMSO- $\left.d_{6}\right): 59.8,59.9\left(\mathrm{C}_{6^{\prime}}, \mathrm{CH}_{2}\right), 64.5\left(\mathrm{C}_{2^{\prime}}\right)$, $66.6\left(\mathrm{C}_{4^{\prime}}\right), 73.0\left(\mathrm{C}_{3^{\prime}}\right), 79.8\left(\mathrm{C}_{1^{\prime}}\right), 80.6\left(\mathrm{C}_{5^{\prime}}\right), 109.6,113.4$, $117.2,120.2,120.3,123.3,129.7,130.2,140.8,151.7(\mathrm{C}$ quat arom), 111.8, 117.5, 122.1, 124.4, 127.7, 133.7, 144.9 $(\mathrm{C}$ tert arom $), 168.5,168.6(\mathrm{C}=\mathrm{O})$.

4.1.12. 5,7-Dihydro-12,13-( $\beta$-D-mannopyranose-1,2diyl)-6H-pyrrolo $[3,4-c]$ pyrido $\left[2^{\prime}, 3^{\prime}: 4,5\right]$ pyrrolo $[2,3-a]$ carbazole-5,7-dione 12. To a solution of $11(30 \mathrm{mg}$, $0.060 \mathrm{mmol})$ in THF $(6 \mathrm{~mL})$ was added $28 \%$ aqueous $\mathrm{NH}_{4} \mathrm{OH}(12 \mathrm{~mL})$. The mixture was stirred overnight at room temperature. The solvent was removed and the residue was purified by flash chromatography (eluent $\mathrm{CH}_{2} \mathrm{Cl}_{2} / \mathrm{MeOH}$ 95:5) to give $12(20 \mathrm{mg}, 0.0425 \mathrm{mmol}, 71 \%$ yield) as a yellow solid.

Compound 12. $\mathrm{Mp}>300^{\circ} \mathrm{C}$. IR $(\mathrm{KBr}) \nu_{\mathrm{C}=\mathrm{O}} 1620$, $1670 \mathrm{~cm}^{-1}, \nu_{\mathrm{NH}, \mathrm{OH}} 3200-3500 \mathrm{~cm}^{-1}$. Mass (APCI+) $[\mathrm{M}+\mathrm{H}]^{+}=471$. HRMS $(\mathrm{FAB}+)[\mathrm{M}+\mathrm{H}]^{+}$, calcd for $\mathrm{C}_{25} \mathrm{H}_{18} \mathrm{~N}_{4} \mathrm{O}_{6}$ 471.1304, found 471.1300. ${ }^{1} \mathrm{H}$ NMR $\left(400 \mathrm{MHz}\right.$, DMSO- $\left.d_{6}\right): 3.30\left(1 \mathrm{H}, \mathrm{m}, \mathrm{H}_{6^{\prime}}\right), 3.46-3.59(2 \mathrm{H}$, $\left.\mathrm{m}, \mathrm{H}_{4^{\prime}}+\mathrm{H}_{6^{\prime}}\right), 3.70\left(1 \mathrm{H}, \mathrm{m}, \mathrm{H}_{5^{\prime}}\right), 4.29\left(1 \mathrm{H}, \mathrm{dt}, J_{1}=12.5 \mathrm{~Hz}\right.$, $\left.J_{2}=3.0 \mathrm{~Hz}, \mathrm{H}_{3^{\prime}}\right), 4.35\left(1 \mathrm{H}, \mathrm{t}, J=5.5 \mathrm{~Hz}, \mathrm{OH}_{6^{\prime}}\right), 5.28(1 \mathrm{H}, \mathrm{d}$, $\left.J=2.0 \mathrm{~Hz}, \mathrm{H}_{2^{\prime}}\right), 5.47\left(1 \mathrm{H}, \mathrm{d}, J=5.0 \mathrm{~Hz}, \mathrm{OH}_{4^{\prime}}\right), 6.93(1 \mathrm{H}, \mathrm{s}$, $\left.\mathrm{H}_{1^{\prime}}\right), 7.48(1 \mathrm{H}, \mathrm{t}, J=7.5 \mathrm{~Hz}), 7.60\left(1 \mathrm{H}, \mathrm{dd}, J_{1}=7.5 \mathrm{~Hz}\right.$, 
$\left.J_{2}=5.0 \mathrm{~Hz}\right), 7.68\left(1 \mathrm{H}, \mathrm{t}, J_{1}=8.0 \mathrm{~Hz}\right), 8.00(1 \mathrm{H}, \mathrm{d}, J=$ $8.0 \mathrm{~Hz}), 8.22\left(1 \mathrm{H}, \mathrm{d}, J=12.0 \mathrm{~Hz}, \mathrm{OH}_{3^{\prime}}\right), 8.60-8.67(2 \mathrm{H}, \mathrm{m})$, $9.00(1 \mathrm{H}, \mathrm{d}, J=7.5 \mathrm{~Hz}), 11.17(1 \mathrm{H}, \mathrm{s}, \mathrm{NH}) .{ }^{13} \mathrm{C} \mathrm{NMR}$ $\left(100 \mathrm{MHz}, \mathrm{DMSO}-d_{6}\right): 59.9\left(\mathrm{C}_{6^{\prime}}\right), 64.4,66.6,73.0,79.8$, $80.6\left(\mathrm{C}_{1^{\prime}}, \mathrm{C}_{2^{\prime}}, \mathrm{C}_{3^{\prime}}, \mathrm{C}_{4^{\prime}}, \mathrm{C}_{5^{\prime}}\right), 109.5,113.4,117.4,121.5$, $121.6,123.5,129.6,130.1,140.8,151.7$ (C quat arom), $111.8,117.3,122.0,124.5,127.5,133.9,144.7$ (C tert arom), $170.6(2 \mathrm{C}=\mathrm{O})$.

4.1.13. 3,4-Di- $O$-benzyl-6- $O$-tosyl-D-glucal 13 . To a solution of glucal $\mathbf{E}(700 \mathrm{mg}, 2.14 \mathrm{mmol})$ in pyridine $(3 \mathrm{~mL})$ and $\mathrm{CH}_{2} \mathrm{Cl}_{2}(7.5 \mathrm{~mL})$ was added tosyl chloride $(1.45 \mathrm{~g}$, $7.6 \mathrm{mmol})$. The mixture was refluxed overnight, then $2 \mathrm{~N}$ $\mathrm{HCl}(15 \mathrm{~mL})$ was added. After extraction with EtOAc, the organic phase was washed with saturated aqueous $\mathrm{NaHCO}_{3}$ then with brine, dried over $\mathrm{MgSO}_{4}$, the solvent was removed and the residue was purified by flash chromatography (eluent cyclohexane/EtOAc 9:1) to give 13 (503 mg, $1.048 \mathrm{mmol}, 49 \%$ yield) as a colorless oil.

Compound 13. IR ( $\mathrm{NaCl}$ film) $\nu_{\mathrm{C}=\mathrm{O}} 1647,1733 \mathrm{~cm}^{-1}$. Mass (ESI+) $[\mathrm{M}+\mathrm{Na}]^{+} 503 .{ }^{1} \mathrm{H}$ NMR $(400 \mathrm{MHz}$, $\left.\mathrm{CDCl}_{3}\right): 2.45\left(3 \mathrm{H}, \mathrm{s}, \mathrm{CH}_{3}\right), 3.84\left(1 \mathrm{H}, \mathrm{dd}, J_{1}=8.0 \mathrm{~Hz}, J_{2}=\right.$ $\left.6.0 \mathrm{~Hz}, \mathrm{H}_{4}\right), 4.16\left(1 \mathrm{H}, \mathrm{m}, \mathrm{H}_{5}\right), 4.22\left(1 \mathrm{H}, \mathrm{m}, \mathrm{H}_{3}\right), 4.34(1 \mathrm{H}$, dd, $\left.J_{1}=11.0 \mathrm{~Hz}, J_{2}=2.5 \mathrm{~Hz}, \mathrm{H}_{6}\right), 4.45\left(1 \mathrm{H}, \mathrm{dd}, J_{1}=\right.$ $\left.11.0 \mathrm{~Hz}, J_{2}=5.5 \mathrm{~Hz}, \mathrm{H}_{6}\right), 4.57(1 \mathrm{H}, \mathrm{d}, J=12.0 \mathrm{~Hz}), 4.68$ $(1 \mathrm{H}, \mathrm{d}, J=11.0 \mathrm{~Hz}), 4.69(1 \mathrm{H}, \mathrm{d}, J=11.0 \mathrm{~Hz}), 4.89(1 \mathrm{H}, \mathrm{d}$, $J=11.0 \mathrm{~Hz}), 4.96\left(1 \mathrm{H}, \mathrm{dd}, J_{1}=6.5 \mathrm{~Hz}, J_{2}=3.0 \mathrm{~Hz}, \mathrm{H}_{2}\right)$, $6.35\left(1 \mathrm{H}, \mathrm{d}, J=6.0 \mathrm{~Hz}, \mathrm{H}_{1}\right), 7.30-7.45(12 \mathrm{H}, \mathrm{m}), 7.85(2 \mathrm{H}$, d, $J=8.0 \mathrm{~Hz}) .{ }^{13} \mathrm{C}$ NMR $\left(100 \mathrm{MHz}, \mathrm{CDCl}_{3}\right): 21.7\left(\mathrm{CH}_{3}\right)$, 68.2, 70.4, $73.5\left(\mathrm{C}_{6}+2 \mathrm{CH}_{2}\right), 73.4,74.5,74.7\left(\mathrm{C}_{3}, \mathrm{C}_{4}, \mathrm{C}_{5}\right)$, $100.1\left(\mathrm{C}_{2}\right), 127.6-128.9,129.9\left(\mathrm{C}\right.$ tert arom), $144\left(\mathrm{C}_{1}\right)$, $132.8,137.9,138.2,145.0$ (C quat arom).

4.1.14. 1- $O$-Acetyl-3,4-di- $O$-benzyl-6- $O$-tosyl- $\alpha$ - and $\beta$-Dglucopyranose $\mathbf{1 5}$. To a solution of $\mathbf{1 3}(291 \mathrm{mg}$, $0.606 \mathrm{mmol})$ in $\mathrm{CH}_{2} \mathrm{Cl}_{2}(6 \mathrm{~mL})$ at $0{ }^{\circ} \mathrm{C}$ was added a solution of dimethyldioxirane in acetone $(0.07-0.09 \mathrm{M}, 20 \mathrm{~mL})$. The mixture was stirred at $0{ }^{\circ} \mathrm{C}$ for $1 \mathrm{~h}$, the solvent was removed at room temperature and compound $\mathbf{1 4}$ was dried under vacuum for $2 \mathrm{~h}$. Glacial acetic acid $(6 \mathrm{~mL})$ was added to $\mathbf{1 4}$ under nitrogen atmosphere. The mixture was stirred at room temperature overnight. After evaporation of acetic acid, the residue was dissolved in $\mathrm{CH}_{2} \mathrm{Cl}_{2}$ then saturated aqueous $\mathrm{NaHCO}_{3}$ was added. After extraction with EtOAc, the organic phase was dried over $\mathrm{MgSO}_{4}$, the solvent was removed and the residue was purified by flash chromatography (eluent cyclohexane/EtOAc from $8: 2$ to $7: 3$ ) to give 15 (258 $\mathrm{mg}, 0.465 \mathrm{mmol}, 77 \%$ yield from E) as a colorless oil. The anomeric ratio calculated from ${ }^{1} \mathrm{H}$ NMR spectrum on $\mathrm{H}_{1^{\prime}}$ at $5.98 \mathrm{ppm}(\alpha$ anomer) and $5.34 \mathrm{ppm}$ ( $\beta$ anomer) was $0.3: 2$, respectively.

Compound 15. IR (NaCl film) $\nu_{\mathrm{C}=\mathrm{O}} 1710,1757 \mathrm{~cm}^{-1}, \nu_{\mathrm{OH}}$ $3517 \mathrm{~cm}^{-1}$. Mass (ESI+) $[\mathrm{M}+\mathrm{Na}]^{+} 579 .{ }^{1} \mathrm{H}$ NMR $\left(400 \mathrm{MHz}, \mathrm{CDCl}_{3}\right)$ of the major anomer: $2.00(3 \mathrm{H}, \mathrm{s}$, $\left.\mathrm{CH}_{3}\right), 2.30\left(3 \mathrm{H}, \mathrm{s}, \mathrm{CH}_{3}\right), 2.54(1 \mathrm{H}$, br s, $\mathrm{OH}), 3.49(4 \mathrm{H}, \mathrm{br} \mathrm{s})$, $4.11(1 \mathrm{H}, \mathrm{d}, J=10.5 \mathrm{~Hz}), 4.17(1 \mathrm{H}, \mathrm{d}, J=10.0 \mathrm{~Hz}), 4.43$ $(1 \mathrm{H}, \mathrm{d}, J=10.5 \mathrm{~Hz}), 4.73(1 \mathrm{H}, \mathrm{d}, J=10.5 \mathrm{~Hz}), 4.77(1 \mathrm{H}, \mathrm{s})$, $4.78(1 \mathrm{H}, \mathrm{d}, J=8.5 \mathrm{~Hz}), 5.34\left(1 \mathrm{H}, \mathrm{d}, J=7.0 \mathrm{~Hz}, \mathrm{H}_{1}\right), 7.08-$ $7.29(12 \mathrm{H}, \mathrm{m}), 7.67(2 \mathrm{H}, \mathrm{d}, J=8.5 \mathrm{~Hz}) .{ }^{13} \mathrm{C}$ NMR $\left(100 \mathrm{MHz}, \mathrm{CDCl}_{3}\right)$ of the major anomer: $20.9,21.6\left(\mathrm{CH}_{3}\right)$, $67.8\left(\mathrm{C}_{6^{\prime}}\right), 74.9,75.3\left(\mathrm{CH}_{2}\right), 72.8,73.5,76.1,84.3,93.7\left(\mathrm{C}_{1^{\prime}}\right.$,
$\left.\mathrm{C}_{2^{\prime}}, \mathrm{C}_{3^{\prime}}, \mathrm{C}_{4^{\prime}}, \mathrm{C}_{5^{\prime}}\right), 127.6-128.6,129.9$ (C tert arom), 132.6, 137.5, 138.2, 145.0 (C quat arom), 169.4; $169.5(\mathrm{C}=\mathrm{O})$.

4.1.15. 1- $O$-Acetyl-3,4-di- $O$-benzyl-2,6-di- $O$-tosyl- $\alpha$ - and $\boldsymbol{\beta}$-D-glucopyranose 16. To a solution of $\mathbf{1 5}(558 \mathrm{mg}$, $1.00 \mathrm{mmol})$ in pyridine $(2 \mathrm{~mL})$ and $\mathrm{CH}_{2} \mathrm{Cl}_{2}(4 \mathrm{~mL})$ was added tosyl chloride $(315 \mathrm{mg}, 1.65 \mathrm{mmol})$. The mixture was refluxed for $72 \mathrm{~h}$, then $2 \mathrm{~N} \mathrm{HCl}(15 \mathrm{~mL})$ was added. After extraction with EtOAc, the organic phase was washed with saturated aqueous $\mathrm{NaHCO}_{3}$ then with brine, dried over $\mathrm{MgSO}_{4}$, the solvent was removed and the residue was purified by flash chromatography (eluent cyclohexane/ EtOAc from 8:2 to 7:3) to give $\mathbf{1 6}(171 \mathrm{mg}, 0.241 \mathrm{mmol}$, $24 \%$ yield) as a colorless oil. The anomeric ratio calculated from ${ }^{1} \mathrm{H}$ NMR spectrum on $\mathrm{H}_{1^{\prime}}$ at $6.15 \mathrm{ppm},(\alpha$ anomer $)$ and $5.62 \mathrm{ppm}$ ( $\beta$ anomer) was $1: 3.9$, respectively. $171 \mathrm{mg}$ of unreacted 15 ( $\beta$ anomer) was recovered.

Compound 16. ${ }^{\beta}$ Major anomer, ${ }^{\alpha}$ minor anomer. IR (NaCl film) $\nu_{\mathrm{C}=\mathrm{O}} 1737,1767 \mathrm{~cm}^{-1}$. Mass $(\mathrm{ESI}+)[\mathrm{M}+\mathrm{Na}]^{+}$ 733. ${ }^{1} \mathrm{H}$ NMR $\left(400 \mathrm{MHz}, \mathrm{CDCl}_{3}\right): 2.06\left(3 \mathrm{H}^{\beta}, \mathrm{s}, \mathrm{CH}_{3}\right), 2.09$ $\left(3 \mathrm{H}^{\alpha}, \mathrm{s}, \mathrm{CH}_{3}\right), 2.35\left(3 \mathrm{H}^{\beta}, \mathrm{s}, \mathrm{CH}_{3}\right), 2.39\left(3 \mathrm{H}^{\alpha}, \mathrm{s}, \mathrm{CH}_{3}\right), 2.42$ $\left(3 \mathrm{H}^{\beta}, \mathrm{s}, \mathrm{CH}_{3}\right), 2.43\left(3 \mathrm{H}^{\alpha}, \mathrm{s}, \mathrm{CH}_{3}\right), 3.58-4.01\left(\mathrm{~m}, 3 \mathrm{H}^{\beta}+\right.$ $\left.3 \mathrm{H}^{\alpha}\right), 4.19-4.32\left(2 \mathrm{H}^{\beta}+2 \mathrm{H}^{\alpha}, \mathrm{m}\right), 4.43-4.52\left(1 \mathrm{H}^{\alpha}+1 \mathrm{H}^{\beta}, \mathrm{m}\right)$, $4.64-4.73\left(3 \mathrm{H}^{\beta}+3 \mathrm{H}^{\alpha}, \mathrm{m}\right), 4.74-4.80\left(1 \mathrm{H}^{\beta}+1 \mathrm{H}^{\alpha}, \mathrm{m}\right), 5.62$ $\left(1 \mathrm{H}^{\beta}, \mathrm{d}, J=8.0 \mathrm{~Hz}, \mathrm{H}_{1}\right), 6.15\left(1 \mathrm{H}^{\alpha}, \mathrm{d}, J=3.5 \mathrm{~Hz}, \mathrm{H}_{1}\right), 7.10$ $7.40\left(10 \mathrm{H}^{\beta}+10 \mathrm{H}^{\alpha}\right), 7.77\left(2 \mathrm{H}^{\beta}+2 \mathrm{H}^{\alpha}, \mathrm{pt}, J=8.5 \mathrm{~Hz}\right) .{ }^{13} \mathrm{C}$ NMR $\left(100 \mathrm{MHz}, \mathrm{CDCl}_{3}\right): 20.5,20.7\left(\mathrm{CH}_{3}\right), 21.5,21.6$ $\left(\mathrm{CH}_{3}\right), 67.3,67.5\left(\mathrm{C}_{6^{\prime}}\right), 75.2,75.5\left(\mathrm{CH}_{2}\right), 70.7,73.5,76.2$, 76.3, 77.6, 79.2, 82.1, 89.1, 91.1 ( $\left.\mathrm{C}_{1^{\prime}}, \mathrm{C}_{2^{\prime}}, \mathrm{C}_{3^{\prime}}, \mathrm{C}_{4^{\prime}}, \mathrm{C}_{5^{\prime}}\right)$, $127.4-128.5,129.7,129.9$ (C tert arom), 132.4, 132.5, $132.8,134.0,137.1,137.4,137.6,144.8,145.1,145.4(\mathrm{C}$ quat arom), $168.3(\mathrm{C}=\mathrm{O})$.

4.1.16. 3,4-O-Benzyl-2,6-di- $O$-tosyl- $\alpha$-D-glucopyranose 17. To a solution of $16(170 \mathrm{mg}, 0.24 \mathrm{mmol})$ in THF/ $\mathrm{MeOH}(2 \mathrm{~mL}, 1: 1)$ at $0{ }^{\circ} \mathrm{C}$ was added dropwise $1 \mathrm{M}$ $\mathrm{MeONa} / \mathrm{MeOH}(31 \mu \mathrm{L})$. The mixture was stirred at $0{ }^{\circ} \mathrm{C}$ for $2 \mathrm{~h}$, the solvent was removed and the residue was purified by flash chromatography (eluent cyclohexane/ EtOAc 7:3) affording 17 (106 mg, $0.158 \mathrm{mmol}, 66 \%$ yield) as a colorless oil.

Compound 17. IR ( $\mathrm{NaCl}$ film), $\nu_{\mathrm{C}=\mathrm{O}} 1589,1735 \mathrm{~cm}^{-1}, \nu_{\mathrm{OH}}$ $3500 \mathrm{~cm}^{-1}$. Mass $(\mathrm{ESI}+)[\mathrm{M}+\mathrm{Na}]^{+} 691 .{ }^{1} \mathrm{H}$ NMR $\left(400 \mathrm{MHz}, \mathrm{CDCl}_{3}\right): 2.26\left(3 \mathrm{H}, \mathrm{s}, \mathrm{CH}_{3}\right), 2.31\left(3 \mathrm{H}, \mathrm{s}, \mathrm{CH}_{3}\right)$, $3.40(1 \mathrm{H}, \mathrm{t}, J=9.5 \mathrm{~Hz}), 3.55(1 \mathrm{H}, \mathrm{m}), 3.89(1 \mathrm{H}, \mathrm{t}, J=$ $9.5 \mathrm{~Hz}), 3.94(1 \mathrm{H}, \mathrm{d}, J=10.0 \mathrm{~Hz}), 4.06\left(1 \mathrm{H}, \mathrm{dd}, J_{1}=\right.$ $\left.10.5 \mathrm{~Hz}, J_{2}=1.5 \mathrm{~Hz}\right), 4.13\left(1 \mathrm{H}, \mathrm{dd}, J_{1}=11.0 \mathrm{~Hz}, J_{2}=\right.$ $3.5 \mathrm{~Hz}), 4.21\left(1 \mathrm{H}, \mathrm{dd}, J_{1}=10.0 \mathrm{~Hz}, J_{2}=3.5 \mathrm{~Hz}\right), 4.32(1 \mathrm{H}$, $\mathrm{d}, J=10.5 \mathrm{~Hz}), 4.54(2 \mathrm{H}, \mathrm{s}), 4.61(1 \mathrm{H}, \mathrm{d}, J=10.5 \mathrm{~Hz}), 5.24$ $\left(1 \mathrm{H}, \mathrm{d}, J=3.0 \mathrm{~Hz}, \mathrm{H}_{1}\right), 6.97-7.23(14 \mathrm{H}), 7.66(4 \mathrm{H}, \mathrm{pt}, J=$ $10.0 \mathrm{~Hz}) .{ }^{13} \mathrm{C}$ NMR $\left(100 \mathrm{MHz}, \mathrm{CDCl}_{3}\right): 21.6\left(\mathrm{CH}_{3}\right), 68.3$ $\left(\mathrm{C}_{6^{\prime}}\right), 75.1,75.3\left(\mathrm{CH}_{2}\right), 68.4,77.0,78.8,79.6,90.8\left(\mathrm{C}_{1^{\prime}}, \mathrm{C}_{2^{\prime}}\right.$, $\mathrm{C}_{3^{\prime}}, \mathrm{C}_{4^{\prime}}, \mathrm{C}_{5^{\prime}}$ ), 127.4-128.5, 129.9 (C tert arom), 132.6, 133.0, 137.4, 137.8, 145.1 (2C) (C quat arom).

4.1.17. 1-Benzyloxymethyl-2,5-dihydro-3-[1-(3,4-di- $O$ benzyl-2,6-di- $O$-tosyl- $\beta$-D-glucopyranos-1-yl)-indol-3yl]-4-[1-phenylsulfonyl-pyrrolo[2,3-b]pyridin-3-yl]-pyrrole-2,5-dione 18 . To a solution of $\mathbf{B}(41 \mathrm{mg}, 0.070 \mathrm{mmol})$ in THF (4 mL) were added $17(104 \mathrm{mg}, 0.155 \mathrm{mmol})$ and triphenylphosphine $(41 \mathrm{mg}, 0.155 \mathrm{mmol})$. The mixture was 
cooled to $-78^{\circ} \mathrm{C}$ then diisopropyl azodicarboxylate (DIAD) $(30 \mu \mathrm{M}, 0.155 \mathrm{mmol})$ was added dropwise. The mixture was allowed to reach room temperature then was stirred for $18 \mathrm{~h}$. Water was added. After extraction with EtOAc, the organic phase was dried over $\mathrm{MgSO}_{4}$, the solvent was removed and the residue was purified by flash chromatography (eluent cyclohexane/EtOAc 8:2 then $\left.\mathrm{CH}_{2} \mathrm{Cl}_{2} / \mathrm{EtOAc} 9: 1\right)$ to give 18 (45 mg, $0.036 \mathrm{mmol}, 52 \%$ yield) as a red solid.

Compound 18. Mp $65-68{ }^{\circ} \mathrm{C}$. IR $(\mathrm{KBr}) \nu_{\mathrm{C}=\mathrm{O}} 1708$, $1760 \mathrm{~cm}^{-1}$. Mass $(\mathrm{ESI}+)[\mathrm{M}+\mathrm{Na}]^{+} 1261 .{ }^{1} \mathrm{H}$ NMR $\left(400 \mathrm{MHz}, \mathrm{CDCl}_{3}\right): 2.02\left(3 \mathrm{H}, \mathrm{s}, \mathrm{CH}_{3}\right), 2.19\left(3 \mathrm{H}, \mathrm{s}, \mathrm{CH}_{3}\right)$, $3.68(1 \mathrm{H}, \mathrm{m}), 3.75-3.84(2 \mathrm{H}, \mathrm{m}), 4.05\left(1 \mathrm{H}, \mathrm{dd}, J_{1}=11.0 \mathrm{~Hz}\right.$, $\left.J_{2}=2.0 \mathrm{~Hz}\right), 4.17\left(1 \mathrm{H}, \mathrm{dd}, J_{1}=11.0 \mathrm{~Hz}, J_{2}=4.0 \mathrm{~Hz}\right), 4.53$ $(2 \mathrm{H}, \mathrm{t}, J=10.5 \mathrm{~Hz}), 4.64(1 \mathrm{H}, \mathrm{d}, J=11.0 \mathrm{~Hz}), 4.67(2 \mathrm{H}, \mathrm{s})$, $4.73(1 \mathrm{H}, \mathrm{d}, J=10.5 \mathrm{~Hz}), 5.10(1 \mathrm{H}, \mathrm{m}), 5.17(2 \mathrm{H}, \mathrm{AB}$ system, $J=11.0 \mathrm{~Hz}, \Delta \nu=5 \mathrm{~Hz}), 5.37(1 \mathrm{H}, \mathrm{d}, J=9.0 \mathrm{~Hz}$, $\left.\mathrm{H}_{1^{\prime}}\right), 6.34-6.42(2 \mathrm{H}, \mathrm{m}), 6.66(2 \mathrm{H}, \mathrm{d}, J=8.0 \mathrm{~Hz}), 6.71(1 \mathrm{H}$, $\left.\mathrm{dd}, J_{1}=8.0 \mathrm{~Hz}, J_{2}=5.0 \mathrm{~Hz}\right), 6.94\left(1 \mathrm{H}, \mathrm{dt}, J_{1}=7.0 \mathrm{~Hz}, J_{2}=\right.$ $1.5 \mathrm{~Hz}), 7.03(2 \mathrm{H}, \mathrm{d}, J=8.0 \mathrm{~Hz}), 7.05-7.10(2 \mathrm{H}, \mathrm{m}), 7.11-$ $7.29(14 \mathrm{H}), 7.30-7.35(3 \mathrm{H}, \mathrm{m}), 7.42(2 \mathrm{H}, \mathrm{t}, J=8.5 \mathrm{~Hz}), 7.53$ $(1 \mathrm{H}, \mathrm{t}, J=7.5 \mathrm{~Hz}), 7.63(2 \mathrm{H}, \mathrm{d}, J=8.0 \mathrm{~Hz}), 7.90(1 \mathrm{H}, \mathrm{s})$, $8.07\left(2 \mathrm{H}, \mathrm{dd}, J_{1}=8.5 \mathrm{~Hz}, J_{2}=1.5 \mathrm{~Hz}\right), 8.10(1 \mathrm{H}, \mathrm{s}), 8.16$ $\left(1 \mathrm{H}, \mathrm{dd}, J_{1}=5.0 \mathrm{~Hz}, J_{2}=1.5 \mathrm{~Hz}\right) .{ }^{13} \mathrm{C}$ NMR $(100 \mathrm{MHz}$, $\left.\mathrm{CDCl}_{3}\right): 21.5\left(\mathrm{CH}_{3}\right), 21.6\left(\mathrm{CH}_{3}\right), 67.4,67.5\left(\mathrm{CH}_{2}\right), 71.8$ $\left(\mathrm{C}_{6^{\prime}}\right), 75.3,75.5\left(\mathrm{CH}_{2}\right), 75.9,76.6,79.4,82.9\left(\mathrm{C}_{1^{\prime}}, \mathrm{C}_{2^{\prime}}, \mathrm{C}_{3^{\prime}}\right.$, $\left.\mathrm{C}_{4^{\prime}}, \mathrm{C}_{5^{\prime}}\right), 119.4,121.5,123.2,127.0-130.0,131.4,134.2$, 145.5 (C tert arom), 106.9, 109.4, 121.2, 124.1, 126.0, $130.8,132.1,133.1,135.6,136.8,137.4,137.6,138.0$, 144.5, 145.1, 146.6 (C quat arom), $170.6(\mathrm{C}=\mathrm{O})$.

4.1.18. 1-Benzyloxymethyl-2,5-dihydro-3-[1-(3,4-di- $O$ benzyl-2,6-di- $O$-tosyl- $\beta$-D-glucopyranos-1-yl)-indol-3yl]-4-[pyrrolo[2,3-b]pyridin-3-yl]-pyrrole-2,5-dione 19. To a solution of $18(45 \mathrm{mg}, 0.036 \mathrm{mmol})$ in THF $(2 \mathrm{~mL})$ was added a $1.1 \mathrm{M}$ solution of tetrabutylammonium fluoride in THF $(109 \mu \mathrm{L}, 0.120 \mathrm{mmol})$. The mixture was stirred for $2.5 \mathrm{~h}$ at room temperature. Water was added. After extraction with EtOAc, the organic phase was dried over $\mathrm{MgSO}_{4}$, the solvent was removed and the residue was purified by flash chromatography (eluent $\mathrm{CH}_{2} \mathrm{Cl}_{2} / \mathrm{EtOAc}$ $4: 1)$ to give $19(33 \mathrm{mg}, 0.030 \mathrm{mmol}, 83 \%$ yield $)$ as a red solid.

Compound 19. Mp $105-107{ }^{\circ} \mathrm{C}$. IR $(\mathrm{KBr}) \nu_{\mathrm{C}=\mathrm{O}} 1708$, $1764 \mathrm{~cm}^{-1}, \nu_{\mathrm{NH}} 3402 \mathrm{~cm}^{-1}$. Mass (ESI+) $[\mathrm{M}+\mathrm{H}]^{+}$ 1099, $[\mathrm{M}+\mathrm{Na}]^{+}$1121. ${ }^{1} \mathrm{H}$ NMR $\left(400 \mathrm{MHz}, \mathrm{CDCl}_{3}\right): 2.01$ $\left(3 \mathrm{H}, \mathrm{s}, \mathrm{CH}_{3}\right), 2.18\left(3 \mathrm{H}, \mathrm{s}, \mathrm{CH}_{3}\right), 3.68(1 \mathrm{H}, \mathrm{m}), 3.72-3.85$ $(2 \mathrm{H}, \mathrm{m}), 4.11(2 \mathrm{H}, \mathrm{br} \mathrm{s}), 4.50(1 \mathrm{H}, \mathrm{d}, J=10.5 \mathrm{~Hz}), 4.64(2 \mathrm{H}$, s), $4.68(2 \mathrm{H}, \mathrm{s}), 4.74(1 \mathrm{H}, \mathrm{d}, J=10.5 \mathrm{~Hz}), 5.13(1 \mathrm{H}, \mathrm{t}, J=$ $8.5 \mathrm{~Hz}), 5.18(2 \mathrm{H}, \mathrm{s}), 5.37\left(1 \mathrm{H}, \mathrm{d}, J=9.0 \mathrm{~Hz}, \mathrm{H}_{1^{\prime}}\right), 6.60-$ $6.70(5 \mathrm{H}, \mathrm{m}), 6.93(1 \mathrm{H}, \mathrm{m}), 7.02(2 \mathrm{H}, \mathrm{d}, J=8.0 \mathrm{~Hz}), 7.06-$ $7.11(2 \mathrm{H}, \mathrm{m}), 7.13-7.28(14 \mathrm{H}), 7.34(2 \mathrm{H}, \mathrm{d}, J=7.5 \mathrm{~Hz})$, $7.43(1 \mathrm{H}, \mathrm{d}, J=8.0 \mathrm{~Hz}), 7.62(2 \mathrm{H}, \mathrm{d}, J=8.0 \mathrm{~Hz}), 7.78(1 \mathrm{H}$, s), $7.89(1 \mathrm{H}, \mathrm{s}), 8.03\left(1 \mathrm{H}\right.$, br s), $11.57\left(1 \mathrm{H}\right.$, br s, NH). ${ }^{13} \mathrm{C}$ NMR $\left(100 \mathrm{MHz}, \mathrm{CDCl}_{3}\right): 21.5\left(\mathrm{CH}_{3}\right), 21.6\left(\mathrm{CH}_{3}\right), 67.3$, $67.5\left(\mathrm{CH}_{2}\right), 71.7\left(\mathrm{C}_{6^{\prime}}\right), 75.4(2 \mathrm{C})\left(\mathrm{CH}_{2}\right), 75.8,75.9,76.7$, 79.6, 83.0 $\left(\mathrm{C}_{1^{\prime}}, \mathrm{C}_{2^{\prime}}, \mathrm{C}_{3^{\prime}}, \mathrm{C}_{4^{\prime}}, \mathrm{C}_{5^{\prime}}\right), 116.9,121.1,122.1$, $123.0,127.0-130.0,131.5,143.0$ (C tert arom), 105.5, $107.6,119.0,126.4,127.0,132.2,133.1,135.6,136.9$, $137.5,137.7,144.4,144.5,145.1,148.3$ (C quat arom), $171.3,171.6(\mathrm{C}=\mathrm{O})$.
4.1.19. 12-(3,4-Di- $O$-benzyl-2,6-di- $O$-tosyl- $\beta$-D-glucopyranos-1-yl)-13H-2,5-dihydro-pyrido $\left[3^{\prime}, 2^{\prime}: 4,5\right] \mathrm{pyr}$ rolo[2,3-a]-pyrrolo[3,4-c]carbazole-5,7-dione 20 . To a solution of $19(381 \mathrm{mg}, 0.346 \mathrm{mmol})$ in benzene $(300 \mathrm{~mL})$ was added iodine $(137 \mathrm{mg}, 0.52 \mathrm{mmol})$. The mixture was irradiated for $1 \mathrm{~h}$ with a medium pressure mercury lamp $(400 \mathrm{~W})$. The solvent was removed, and the residue dissolved in EtOAc $(250 \mathrm{~mL})$ and washed with saturated aqueous sodium thiosulfate $(50 \mathrm{~mL})$ and then with brine. The organic phase was dried over $\mathrm{MgSO}_{4}$, the solvent was removed and the residue was purified by flash chromatography (eluent $\mathrm{CH}_{2} \mathrm{Cl}_{2} /$ EtOAc 9:1) to give 20 (228 mg, $0.208 \mathrm{mmol}, 60 \%$ yield) as a yellow solid.

Compound 20. Mp $82-85^{\circ} \mathrm{C}$. IR $(\mathrm{KBr}) \nu_{\mathrm{C}=\mathrm{O}} 1710$, $1760 \mathrm{~cm}^{-1}, \nu_{\mathrm{NH}} 3300-3500 \mathrm{~cm}^{-1}$. Mass (APCI+) $[\mathrm{M}]^{+}$ 1097. ${ }^{1} \mathrm{H}$ NMR $\left(400 \mathrm{MHz}, \mathrm{CDCl}_{3}\right): 1.99\left(6 \mathrm{H}, \mathrm{s}, \mathrm{CH}_{3}\right), 3.84$ $\left(1 \mathrm{H}, \mathrm{t}, J=6.0 \mathrm{~Hz}, \mathrm{H}_{4^{\prime}}\right), 4.19\left(1 \mathrm{H}, \mathrm{t}, J=5.5 \mathrm{~Hz}, \mathrm{H}_{3^{\prime}}\right), 4.28$ $\left(1 \mathrm{H}, \mathrm{m}, \mathrm{H}_{5^{\prime}}\right), 4.34(2 \mathrm{H}, \mathrm{d}, J=11.0 \mathrm{~Hz}), 4.42\left(1 \mathrm{H}, \mathrm{dd}, J_{1}=\right.$ $\left.11.0 \mathrm{~Hz}, J_{2}=5.5 \mathrm{~Hz}\right), 4.61(1 \mathrm{H}, \mathrm{d}, J=11.5 \mathrm{~Hz}), 4.70(1 \mathrm{H}, \mathrm{d}$, $J=9.0 \mathrm{~Hz}), 4.72(2 \mathrm{H}, \mathrm{s}), 5.06\left(1 \mathrm{H}, \mathrm{dd}, J_{1}=9.0 \mathrm{~Hz}, J_{2}=\right.$ $4.5 \mathrm{~Hz}), 5.15(1 \mathrm{H}, \mathrm{d}, J=11.0 \mathrm{~Hz}), 5.27(2 \mathrm{H}, \mathrm{s}), 6.04(1 \mathrm{H}, \mathrm{d}$, $\left.J=9.0 \mathrm{~Hz}, \mathrm{H}_{1^{\prime}}\right), 6.19(2 \mathrm{H}, \mathrm{d}, J=8.0 \mathrm{~Hz}), 6.47(2 \mathrm{H}, \mathrm{d}, J=$ $7.5 \mathrm{~Hz}), 6.69(2 \mathrm{H}, \mathrm{d}, J=8.0 \mathrm{~Hz}), 7.10-7.30(19 \mathrm{H}, \mathrm{m}), 7.50$ $(2 \mathrm{H}, \mathrm{d}, J=7.5 \mathrm{~Hz}), 8.50(1 \mathrm{H}, \mathrm{d}, J=4.5 \mathrm{~Hz}), 8.99(1 \mathrm{H}, \mathrm{d}$, $J=8.0 \mathrm{~Hz}), 9.33(1 \mathrm{H}, \mathrm{d}, J=8.0 \mathrm{~Hz}), 10.07(1 \mathrm{H}, \mathrm{s}) .{ }^{13} \mathrm{C}$ NMR $\left(100 \mathrm{MHz}, \mathrm{CDCl}_{3}\right): 21.1\left(\mathrm{CH}_{3}\right), 21.4\left(\mathrm{CH}_{3}\right), 66.9$, 68.4, 71.7, 73.7, $74.0\left(\mathrm{CH}_{2}\right), 74.6,78.6,79.0,79.6,81.3$ $\left(\mathrm{C}_{1^{\prime}}, \mathrm{C}_{2^{\prime}}, \mathrm{C}_{3^{\prime}}, \mathrm{C}_{4^{\prime}}, \mathrm{C}_{5^{\prime}}\right), 109.3,117.6,121.9,125.7,126.1$, $127.0-129.0,129.4,133.7,148.3$ (C tert arom), 114.7, $116.4,119.1,119.9,120.8,121.7,126.9,131.1,132.4$, $136.4,136.7,137.6,140.6,144.5,144.8,152.7$ (C quat arom), $169.2(2 \mathrm{C}=\mathrm{O})$.

4.1.20. 6-Benzyloxymethyl-5,7-dihydro-12,13-(6-azido3,4-di $O$-benzyl-6-deoxy- $\beta$-D-mannopyranose-1,2-diyl)pyrido $\left[3^{\prime}, 2^{\prime}: 4,5\right]$ pyrrolo $[2,3-a]$ pyrrolo $[3,4-c]$ carbazole$\mathbf{5 , 7 - d i o n e ~ 2 1 . ~ T o ~ a ~ s o l u t i o n ~ o f ~} \mathbf{2 0}(12.5 \mathrm{mg}, 0.011 \mathrm{mmol})$ in DMF $(1 \mathrm{~mL})$ was added $\mathrm{NaN}_{3}(7.3 \mathrm{mg}, 0.112 \mathrm{mmol})$. The mixture was stirred overnight at $70^{\circ} \mathrm{C}$. Water was added. After extraction with EtOAc, the organic phase was dried over $\mathrm{MgSO}_{4}$, the solvent was removed and the residue was purified by flash chromatography (eluent $\mathrm{CH}_{2} \mathrm{Cl}_{2} 100 \%$ to $\mathrm{CH}_{2} \mathrm{Cl}_{2} /$ EtOAc 9:1) to give 21 (7.5 mg, $0.0094 \mathrm{mmol}, 82 \%$ yield) as a yellow solid.

Compound 21. Mp $45-47^{\circ} \mathrm{C}$. IR $(\mathrm{KBr}) \nu_{\mathrm{C}=\mathrm{O}} 1704$, $1754 \mathrm{~cm}^{-1}, \nu_{\mathrm{N} 3} 2100 \mathrm{~cm}^{-1}$. Mass (ESI +$)[\mathrm{M}+\mathrm{H}]^{+} 796$. ${ }^{1} \mathrm{H}$ NMR $\left(400 \mathrm{MHz}, \mathrm{CDCl}_{3}\right): 3.62\left(1 \mathrm{H}, \mathrm{dd}, J_{1}=13.0 \mathrm{~Hz}\right.$, $\left.J_{2}=6.0 \mathrm{~Hz}, \mathrm{H}_{6^{\prime}}\right), 3.66\left(1 \mathrm{H}, \mathrm{dd}, J_{1}=13.0 \mathrm{~Hz}, J_{2}=7.0 \mathrm{~Hz}\right.$, $\left.\mathrm{H}_{6^{\prime}}\right), 3.79\left(1 \mathrm{H}, \mathrm{m}, \mathrm{H}_{4^{\prime}}\right), 3.76(1 \mathrm{H}, \mathrm{m}), 3.81(1 \mathrm{H}, \mathrm{d}, J=$ $13.0 \mathrm{~Hz}), 3.87(1 \mathrm{H}, \mathrm{d}, J=12.0 \mathrm{~Hz}), 4.22\left(1 \mathrm{H}, \mathrm{dd}, J_{1}=\right.$ $\left.11.0 \mathrm{~Hz}, J_{2}=6.5 \mathrm{~Hz}, \mathrm{H}_{5^{\prime}}\right), 4.53(1 \mathrm{H}, \mathrm{d}, J=12.0 \mathrm{~Hz}), 4.69$ $\left(1 \mathrm{H}, \mathrm{m}, \mathrm{H}_{3^{\prime}}\right), 4.70(1 \mathrm{H}, \mathrm{d}, J=11.5 \mathrm{~Hz}), 4.78(2 \mathrm{H}, \mathrm{s}), 5.32$ $(2 \mathrm{H}, \mathrm{s}), 5.69\left(1 \mathrm{H}, \mathrm{dd}, J_{1}=5.5 \mathrm{~Hz}, J_{2}=3.5 \mathrm{~Hz}, \mathrm{H}_{2^{\prime}}\right), 6.34$ $\left(1 \mathrm{H}, \mathrm{d}, J=6.0 \mathrm{~Hz}, \mathrm{H}_{1^{\prime}}\right), 6.37(2 \mathrm{H}, \mathrm{d}, J=7.5 \mathrm{~Hz}), 6.87(2 \mathrm{H}, \mathrm{t}$, $J=7.5 \mathrm{~Hz}), 6.99(1 \mathrm{H}, \mathrm{t}, J=7.5 \mathrm{~Hz}), 7.20-7.50(11 \mathrm{H}, \mathrm{m})$, $7.60(1 \mathrm{H}, \mathrm{t}, J=7.5 \mathrm{~Hz}), 7.94(1 \mathrm{H}, \mathrm{d}, J=8.0 \mathrm{~Hz}), 8.48(1 \mathrm{H}$, $\left.\mathrm{dd}, J_{1}=5.0 \mathrm{~Hz}, J_{2}=1.0 \mathrm{~Hz}\right), 8.85(1 \mathrm{H}, \mathrm{d}, J=8.0 \mathrm{~Hz}), 8.99$ $\left(1 \mathrm{H}, \mathrm{dd}, J_{1}=7.5 \mathrm{~Hz}, J_{2}=0.5 \mathrm{~Hz}\right) .{ }^{13} \mathrm{C} \mathrm{NMR}(100 \mathrm{MHz}$, $\left.\mathrm{CDCl}_{3}\right)$ : $52.5\left(\mathrm{C}_{6^{\prime}}\right), 52.6,73.0,73.4,75.0,80.8\left(\mathrm{C}_{1^{\prime}}, \mathrm{C}_{2^{\prime}}, \mathrm{C}_{3^{\prime}}\right.$, $\left.\mathrm{C}_{4^{\prime}}, \mathrm{C}_{5^{\prime}}\right), 66.8,71.5,72.1,72.5\left(\mathrm{CH}_{2}\right), 109.5,114.4,117.6$, $120.3,120.7,124.7,128.6,135.9,137.0,137.8,142.3,151.7$ 
(C quat arom), 113.0, 117.4, 122.5, 125.5, 127.7-128.9, 133.6, $146.7(\mathrm{C}$ tert arom $), 169.6(2 \mathrm{C}=\mathrm{O})$.

4.1.21. 6-Hydroxymethyl-5,7-dihydro-12,13-(6-azido-6deoxy- $\beta$-D-mannopyranos-1,2-diyl)-pyrido $\left[3^{\prime}, 2^{\prime}: 4,5\right]$ pyrrolo[2,3-a] pyrrolo[3,4-c] carbazole-5,7-dione 22 . To a solution of 21 (96 mg, $0.120 \mathrm{mmol})$ in $\mathrm{CH}_{2} \mathrm{Cl}_{2}(6 \mathrm{~mL})$ was added a solution of dimethyldioxirane in acetone $(0.07-$ $0.09 \mathrm{M}, 60 \mathrm{~mL}$ ) during 7 days. After removal of the solvent, the residue was purified by flash chromatography (eluent from cyclohexane/EtOAc 2:8 to EtOAc 100\%) to give 22 (28.3 mg, $0.054 \mathrm{mmol}, 45 \%$ yield).

Compound 22. Mp $145-148{ }^{\circ} \mathrm{C}$. IR $(\mathrm{KBr}) \nu_{\mathrm{C}=\mathrm{O}} 1702$, $1753 \mathrm{~cm}^{-1}, \nu_{\mathrm{N} 3} 2100 \mathrm{~cm}^{-1}, \nu_{\mathrm{OH}} 3038-3653 \mathrm{~cm}^{-1} .{ }^{1} \mathrm{H}$ NMR (400 MHz, DMSO- $\left.d_{6}\right): 3.15\left(1 \mathrm{H}, \mathrm{dd}, J_{1}=13.5 \mathrm{~Hz}\right.$, $\left.J_{2}=6.0 \mathrm{~Hz}, \mathrm{H}_{6^{\prime}}\right), 3.37\left(1 \mathrm{H}, \mathrm{m}, \mathrm{H}_{6^{\prime}}\right), 3.50\left(1 \mathrm{H}, \mathrm{m}, \mathrm{H}_{4^{\prime}}\right), 3.97$ $\left(1 \mathrm{H}, \mathrm{m}, \mathrm{H}_{5^{\prime}}\right), 4.34\left(1 \mathrm{H}, \mathrm{dt}, J_{1}=12.5 \mathrm{~Hz}, J_{2}=3.0 \mathrm{~Hz}, \mathrm{H}_{3^{\prime}}\right)$, $4.90\left(2 \mathrm{H}, \mathrm{m}, \mathrm{CH}_{2} \mathrm{OH}\right), 5.32\left(1 \mathrm{H}, \mathrm{d}, J=2.5 \mathrm{~Hz}, \mathrm{H}_{2^{\prime}}\right), 5.76$ $\left(1 \mathrm{H}, \mathrm{d}, J=5.0 \mathrm{~Hz}, \mathrm{OH}_{4^{\prime}}\right), 6.37\left(1 \mathrm{H}, \mathrm{t}, J=7.0 \mathrm{~Hz}, \mathrm{CH}_{2} \mathrm{OH}\right)$, $7.03\left(1 \mathrm{H}, \mathrm{s}, \mathrm{H}_{1^{\prime}}\right), 7.47(1 \mathrm{H}, \mathrm{t}, J=8.0 \mathrm{~Hz}), 7.57\left(1 \mathrm{H}, \mathrm{dd}, J_{1}=\right.$ $\left.8.0 \mathrm{~Hz}, J_{2}=5.0 \mathrm{~Hz}\right), 7.70\left(1 \mathrm{H}, \mathrm{dt}, J_{1}=8.5 \mathrm{~Hz}, J_{2}=1.0 \mathrm{~Hz}\right)$, $7.98(1 \mathrm{H}, \mathrm{d}, J=8.5 \mathrm{~Hz}), 8.26\left(1 \mathrm{H}, \mathrm{d}, J=12.0 \mathrm{~Hz}, \mathrm{OH}_{3^{\prime}}\right)$, $8.57(1 \mathrm{H}, \mathrm{d}, J=8.0 \mathrm{~Hz}), 8.60\left(1 \mathrm{H}, \mathrm{dd}, J_{1}=4.5 \mathrm{~Hz}, J_{2}=\right.$ $1.5 \mathrm{~Hz}), 8.90\left(1 \mathrm{H}, \mathrm{dd}, J_{1}=8.0 \mathrm{~Hz}, J_{2}=1.5 \mathrm{~Hz}\right) .{ }^{13} \mathrm{C} \mathrm{NMR}$ $\left(100 \mathrm{MHz}\right.$, DMSO-d $\left.d_{6}\right): 50.1\left(\mathrm{C}_{6^{\prime}}\right), 59.6\left(\mathrm{CH}_{2} \mathrm{OH}\right), 64.2$, 67.4, 72.6, 78.8, 79.6 $\left(\mathrm{C}_{1^{\prime}}, \mathrm{C}_{2^{\prime}}, \mathrm{C}_{3^{\prime}}, \mathrm{C}_{4^{\prime}}, \mathrm{C}_{5^{\prime}}\right), 109.6,113.6$, $117.1,120.2,123.4,129.5,130.0,139.1,140.8,151.5(\mathrm{C}$ quat arom), 111.7, 117.5, 122.2, 124.4, 127.7, 133.7, 144.9 (C tert arom), 168.3, $168.4(2 \mathrm{C}=\mathrm{O})$.

4.1.22. 12,13-(6-Azido-6-deoxy- $\beta$-D-mannopyranos-1,2diyl)- $6 H$-pyrido $\left[3^{\prime}, 2^{\prime}: 4,5\right]$ pyrrolo $[2,3-a]$ pyrrolo $[3,4-c]$ carbazole-5,7-dione 23. To a solution of $22(28 \mathrm{mg}$, $0.053 \mathrm{mmol})$ in THF $(6 \mathrm{~mL})$ was added $28 \%$ aqueous $\mathrm{NH}_{4} \mathrm{OH}(11 \mathrm{~mL})$. The mixture was stirred for $5 \mathrm{~h}$ at room temperature. The solvent was removed and the residue was purified by flash chromatography (eluent EtOAc 100\%) to give 23 (20 mg, $0.041 \mathrm{mmol}, 77 \%$ yield) as a yellow solid.

Compound 23. Mp $>200{ }^{\circ} \mathrm{C}$ (decomposition). IR (KBr) $\nu_{\mathrm{C}=\mathrm{O}} 1719,1746 \mathrm{~cm}^{-1}, \nu_{\mathrm{N} 3} 2100 \mathrm{~cm}^{-1}, \nu_{\mathrm{NH}, \mathrm{OH}} 3138-$ $3618 \mathrm{~cm}^{-1}$. HRMS (ESI+) $[\mathrm{M}+\mathrm{H}]^{+}$, calcd for $\mathrm{C}_{25} \mathrm{H}_{18} \mathrm{~N}_{7} \mathrm{O}_{5}$ 496.1369, found 496.1372. ${ }^{1} \mathrm{H}$ NMR $\left(400 \mathrm{MHz}\right.$, DMSO- $\left.d_{6}\right): 3.20\left(1 \mathrm{H}, \mathrm{dd}, J_{1}=13.5 \mathrm{~Hz}, J_{2}=\right.$ $\left.6.0 \mathrm{~Hz}, \mathrm{H}_{6^{\prime}}\right), 3.40\left(1 \mathrm{H}, \mathrm{dd}, J_{1}=13.5 \mathrm{~Hz}, J_{2}=2.0 \mathrm{~Hz}, \mathrm{H}_{6^{\prime}}\right)$, $3.54\left(1 \mathrm{H}, \mathrm{m}, \mathrm{H}_{4^{\prime}}\right), 3.99\left(1 \mathrm{H}, \mathrm{dt}, J_{1}=9.0 \mathrm{~Hz}, J_{2}=2.0 \mathrm{~Hz}\right.$, $\left.\mathrm{H}_{5^{\prime}}\right), 4.31\left(1 \mathrm{H}, \mathrm{dt}, J_{1}=13.0 \mathrm{~Hz}, J_{2}=3.0 \mathrm{~Hz}, \mathrm{H}_{3^{\prime}}\right), 5.40(1 \mathrm{H}$, d, $\left.J=2.5 \mathrm{~Hz}, \mathrm{H}_{2^{\prime}}\right), 5.76\left(1 \mathrm{H}, \mathrm{d}, J=5.0 \mathrm{~Hz}, \mathrm{OH}_{4^{\prime}}\right), 7.05(1 \mathrm{H}$, $\left.\mathrm{s}, \mathrm{H}_{1^{\prime}}\right), 7.53\left(1 \mathrm{H}, \mathrm{dt}, J_{1}=8.0 \mathrm{~Hz}, J_{2}=1.0 \mathrm{~Hz}\right), 7.67(1 \mathrm{H}, \mathrm{dd}$, $\left.J_{1}=8.0 \mathrm{~Hz}, J_{2}=5.0 \mathrm{~Hz}\right), 7.73\left(1 \mathrm{H}, \mathrm{dt}, J_{1}=7.5 \mathrm{~Hz}, J_{2}=\right.$ $1.0 \mathrm{~Hz}), 8.03(1 \mathrm{H}, \mathrm{d}, J=8.0 \mathrm{~Hz}), 8.33(1 \mathrm{H}, \mathrm{d}, J=12.0 \mathrm{~Hz}$, $\left.\mathrm{OH}_{3^{\prime}}\right), 8.66-8.72(2 \mathrm{H}, \mathrm{m}), 9.08\left(1 \mathrm{H}, \mathrm{dd}, J_{1}=8.0 \mathrm{~Hz}, J_{2}=\right.$ $1.5 \mathrm{~Hz}), 11.25(1 \mathrm{H}, \mathrm{s}, \mathrm{NH}) .{ }^{13} \mathrm{C}$ NMR (100 MHz, DMSO$\left.d_{6}\right): 50.2\left(\mathrm{C}_{6^{\prime}}\right), 64.2,67.5,72.7,78.8,79.6\left(\mathrm{C}_{1^{\prime}}, \mathrm{C}_{2^{\prime}}, \mathrm{C}_{3^{\prime}}, \mathrm{C}_{4^{\prime}}\right.$, $\left.\mathrm{C}_{5^{\prime}}\right), 109.6,113.6,117.3,121.1,121.6,123.5,129.5,130.0$, $140.7,151.6$ (C quat arom), 111.7, 117.4, 122.1, 124.5, $127.5,133.9,144.7(\mathrm{C}$ tert arom $), 170.5(2 \mathrm{C}=\mathrm{O})$.

4.1.23. 1-Benzyloxymethyl-3-(1-phenylsulfonyl-1Hindol-3-yl)-4-[1-(2- $O$-tosyl-3,4,6-tri- $O$-benzyl- $\beta$-D-glucopyranos-1-yl)-pyrrolo[2,3-b]pyridin-3-yl]-2,5-dihydropyrrole-2,5-dione 24. To a solution of F (200 mg,
$0.341 \mathrm{mmol})$ in THF $(18 \mathrm{~mL})$ were added 6 (459 mg, $0.76 \mathrm{mmol})$ and triphenylphosphine $(199 \mathrm{mg}, 0.76 \mathrm{mmol})$. The mixture was cooled to $-78{ }^{\circ} \mathrm{C}$ then diisopropyl azodicarboxylate (DIAD) $(147 \mu \mathrm{M}, 0.76 \mathrm{mmol})$ was added dropwise. The mixture was allowed to reach room temperature then was stirred for $18 \mathrm{~h}$. Water was added. After extraction with EtOAc, the organic phase was dried over $\mathrm{MgSO}_{4}$, the solvent was removed and the residue was purified by flash chromatography (eluent $\mathrm{CH}_{2} \mathrm{Cl}_{2} / \mathrm{EtOAc}$ 9:1) to give $\mathbf{2 4}$ as the major product of the reaction $(190 \mathrm{mg}$, $0.161 \mathrm{mmol}, 47 \%$ yield) as a red solid.

Compound 24. Mp $80-82{ }^{\circ} \mathrm{C}$. IR $(\mathrm{KBr}), \nu_{\mathrm{C}=\mathrm{O}} 1711 \mathrm{~cm}^{-1}$. Mass (ESI+) $[\mathrm{M}+\mathrm{H}]^{+} 1175 .{ }^{1} \mathrm{H}$ NMR $(400 \mathrm{MHz}$, $\left.\mathrm{CDCl}_{3}\right): 2.13\left(3 \mathrm{H}, \mathrm{s}, \mathrm{CH}_{3}\right), 3.69-3.80(2 \mathrm{H}, \mathrm{m}), 3.77(1 \mathrm{H}$, d, $J=9.5 \mathrm{~Hz}), 3.91-3.99(2 \mathrm{H}, \mathrm{m}), 4.55(1 \mathrm{H}, \mathrm{d}, J=12.0 \mathrm{~Hz})$, $4.62(1 \mathrm{H}, \mathrm{d}, J=10.5 \mathrm{~Hz}), 4.63(1 \mathrm{H}, \mathrm{d}, J=12.5 \mathrm{~Hz}), 4.65$ $(1 \mathrm{H}, \mathrm{d}, J=12.5 \mathrm{~Hz}), 4.75(1 \mathrm{H}, \mathrm{d}, J=13.5 \mathrm{~Hz}), 4.76(2 \mathrm{H}, \mathrm{s})$, $4.80(1 \mathrm{H}, \mathrm{d}, J=10.5 \mathrm{~Hz}), 5.20\left(1 \mathrm{H}, \mathrm{m}, \mathrm{H}_{2^{\prime}}\right), 5.27(2 \mathrm{H}, \mathrm{s})$, $6.19\left(1 \mathrm{H}, \mathrm{d}, J=9.0 \mathrm{~Hz}, \mathrm{H}_{1^{\prime}}\right), 6.34\left(1 \mathrm{H}, \mathrm{dd}, J_{1}=8.0 \mathrm{~Hz}, J_{2}=\right.$ $4.5 \mathrm{~Hz}), 6.65\left(1 \mathrm{H}, \mathrm{dd}, J_{1}=8.0 \mathrm{~Hz}, J_{2}=1.5 \mathrm{~Hz}\right), 6.75(2 \mathrm{H}, \mathrm{d}$, $J=8.0 \mathrm{~Hz}), 6.84(1 \mathrm{H}, \mathrm{t}, J=7.5 \mathrm{~Hz}), 7.02(1 \mathrm{H}, \mathrm{d}, J=$ $8.0 \mathrm{~Hz}), 7.07-7.13(2 \mathrm{H}, \mathrm{m}), 7.16(1 \mathrm{H}, \mathrm{t}, J=8.0 \mathrm{~Hz}), 7.21-$ $7.40(18 \mathrm{H}), 7.42(2 \mathrm{H}, \mathrm{d}, J=7.5 \mathrm{~Hz}), 7.51(2 \mathrm{H}, \mathrm{t}, J=$ $8.0 \mathrm{~Hz}), 7.63(1 \mathrm{H}, \mathrm{t}, J=7.5 \mathrm{~Hz}), 7.95-8.01(3 \mathrm{H}, \mathrm{m}), 8.06$ $(1 \mathrm{H}, \mathrm{d}, J=1.5 \mathrm{~Hz}), 8.08(1 \mathrm{H}, \mathrm{s}), 8.34(1 \mathrm{H}, \mathrm{s}) .{ }^{13} \mathrm{C} \mathrm{NMR}$ $\left(100 \mathrm{MHz}, \mathrm{CDCl}_{3}\right): 21.5\left(\mathrm{CH}_{3}\right), 67.5,68.2,71.9,73.5,75.3$, $75.4\left(\mathrm{C}_{6^{\prime}}+5 \mathrm{CH}_{2}\right), 77.7,78.2,80.5,83.0\left(\mathrm{C}_{1^{\prime}}, \mathrm{C}_{2^{\prime}}, \mathrm{C}_{3^{\prime}}, \mathrm{C}_{4^{\prime}}\right.$, $\left.\mathrm{C}_{5^{\prime}}\right), 113.5,117.2,122.5,124.0,125.3,127.0-128.6,128.7$, $129.5,129.7,130.5,134.2,143.7$ (C tert arom), 105.8, $112.4,118.6,124.7,130.8,133.5,134.4,137.5,137.7$, $137.9,144.2,147.8$ (C quat arom), $170.5(2 \mathrm{C}, \mathrm{C}=\mathrm{O})$.

4.1.24. 1-Benzyloxymethyl-3-(1H-indol-3-yl)-4-[1-(2-Otosyl-3,4,6-tri- $O$-benzyl- $\beta$-D-glucopyranos- 1 -yl)-pyrrolo[2,3-b]pyridin-3-yl]-2,5-dihydro-pyrrole-2,5-dione 25. To a solution of $24(160 \mathrm{mg}, 0.136 \mathrm{mmol})$ in THF $(5 \mathrm{~mL})$ was added a $1.1 \mathrm{M}$ solution of tetrabutylammonium fluoride in THF $(409 \mu \mathrm{L}, 0.448 \mathrm{mmol})$. The mixture was stirred for $2.5 \mathrm{~h}$ at room temperature. Water was added. After extraction with EtOAc, the organic phase was dried over $\mathrm{MgSO}_{4}$, the solvent was removed and the residue was purified by flash chromatography (eluent from $\mathrm{CH}_{2} \mathrm{Cl}_{2}$ $100 \%$ to $\left.\mathrm{CH}_{2} \mathrm{Cl}_{2} / \mathrm{EtOAc} 9: 1\right)$ to give 25 (90 mg, $0.087 \mathrm{mmol}, 64 \%$ yield) as a red solid.

Compound 25. Mp $38-40{ }^{\circ} \mathrm{C}$. IR $(\mathrm{KBr}) \nu_{\mathrm{C}=\mathrm{O}} 1706$, $1743 \mathrm{~cm}^{-1}, \nu_{\mathrm{NH}} 3163-3608 \mathrm{~cm}^{-1}$. Mass (ESI+) [M+ $\mathrm{H}]^{+}$1035. ${ }^{1} \mathrm{H} \mathrm{NMR}\left(400 \mathrm{MHz}, \mathrm{CDCl}_{3}\right): 2.13\left(3 \mathrm{H}, \mathrm{s}, \mathrm{CH}_{3}\right)$, $3.67(1 \mathrm{H}, \mathrm{d}, J=10.0 \mathrm{~Hz}), 3.72-3.80(2 \mathrm{H}, \mathrm{m}), 3.92(1 \mathrm{H}$, $\mathrm{t}, J=9.0 \mathrm{~Hz}), 3.97(1 \mathrm{H}, \mathrm{t}, J=9.0 \mathrm{~Hz}), 4.47(1 \mathrm{H}, \mathrm{d}, J=$ $12.0 \mathrm{~Hz}), 4.55(1 \mathrm{H}, \mathrm{d}, J=12.0 \mathrm{~Hz}), 4.62(1 \mathrm{H}, \mathrm{d}, J=$ $11.0 \mathrm{~Hz}), 4.80(3 \mathrm{H}, \mathrm{s}+\mathrm{m}), 4.82(1 \mathrm{H}, \mathrm{d}, J=10.5 \mathrm{~Hz}), 5.00$ $(1 \mathrm{H}, \mathrm{m}), 5.27(3 \mathrm{H}, \mathrm{s}+\mathrm{m}), 6.17\left(1 \mathrm{H}, \mathrm{d}, J=9.0 \mathrm{~Hz}, \mathrm{H}_{1^{\prime}}\right), 6.45$ $(1 \mathrm{H}$, br s $), 6.67\left(1 \mathrm{H}, \mathrm{dd}, J_{1}=7.5 \mathrm{~Hz}, J_{2}=4.5 \mathrm{~Hz}\right), 6.72(2 \mathrm{H}$, d, $J=8.0 \mathrm{~Hz}), 6.82(1 \mathrm{H}, \mathrm{t}, J=8.0 \mathrm{~Hz}), 7.00-7.40(23 \mathrm{H})$, $7.44(2 \mathrm{H}, \mathrm{d}, J=7.5 \mathrm{~Hz}), 7.71(1 \mathrm{H}, \mathrm{d}, J=2.0 \mathrm{~Hz}), 8.08(2 \mathrm{H}$, s), $8.88(1 \mathrm{H}, \mathrm{s}, \mathrm{NH}) \cdot{ }^{13} \mathrm{C}$ NMR $\left(100 \mathrm{MHz}, \mathrm{CDCl}_{3}\right): 22.0$ $\left(\mathrm{CH}_{3}\right), 67.3,68.3,71.7,73.5,75.3,75.5\left(\mathrm{C}_{6^{\prime}}+5 \mathrm{CH}_{2}\right), 70.1$, 77.7, 78.1, 80.7, 83.1 $\left(\mathrm{C}_{1^{\prime}}, \mathrm{C}_{2^{\prime}}, \mathrm{C}_{3^{\prime}}, \mathrm{C}_{4^{\prime}}, \mathrm{C}_{5^{\prime}}\right), 111.4,116.9$, $121.1,122.1,122.8,126.8-129.1,129.7,130.5,143.4$ (C tert arom), 106.5, 106.6, 118.9, 125.3, 126.2, 133.5, 135.9, 
137.6, 137.7, 137.8, 138.0, 143.9, 147.7 (C quat arom), $171.2,171.5(\mathrm{C}=\mathrm{O})$.

4.1.25. 6-Benzyloxymethyl-13-(2-O-tosyl-3,4,6-tri-Obenzyl- $\beta$-D-glucopyranos-1-yl)-5,7-dihydro- $12 \mathrm{H}$-pyrido $\left[3^{\prime}, 2^{\prime}: 4,5\right]$ pyrrolo $[3,2-a]$-pyrrolo $[3,4-c]$ carbazole-5,7dione 26. To a solution of $25(54 \mathrm{mg}, 0.052 \mathrm{mmol})$ in DMF $(2 \mathrm{~mL})$ was added $\mathrm{Pd}(\mathrm{OTf})_{2}(52 \mathrm{mg}, 0.158 \mathrm{mmol})$. The mixture was stirred at $90{ }^{\circ} \mathrm{C}$ for $5 \mathrm{~h}$. EtOAc was added, then $0.5 \mathrm{~N} \mathrm{HCl}(10 \mathrm{~mL})$. After extraction with EtOAc, the organic phase was dried over $\mathrm{MgSO}_{4}$, the solvent was removed and the residue was purified by flash chromatography (eluent from cyclohexane/ $\mathrm{CH}_{2} \mathrm{Cl}_{2} 3: 7$ to $\mathrm{CH}_{2} \mathrm{Cl}_{2}$ $100 \%$ ) to give $26(30 \mathrm{mg}, 0.029 \mathrm{mmol}, 56 \%$ yield) as a yellow solid.

Compound 26. Mp $147-149^{\circ} \mathrm{C}$. IR $(\mathrm{KBr}) \nu_{\mathrm{C}=\mathrm{O}} 1710$, $1760 \mathrm{~cm}^{-1}, \nu_{\mathrm{NH}} 3200-3600 \mathrm{~cm}^{-1}$. Mass (ESI+) $[\mathrm{M}+$ $\mathrm{Na}]^{+}$1055. ${ }^{1} \mathrm{H} \mathrm{NMR}\left(400 \mathrm{MHz}, \mathrm{CDCl}_{3}\right): 2.02\left(3 \mathrm{H}, \mathrm{s}, \mathrm{CH}_{3}\right)$, $3.55(1 \mathrm{H}, \mathrm{d}, J=10.0 \mathrm{~Hz}), 3.75(1 \mathrm{H}, \mathrm{d}, J=10.5 \mathrm{~Hz}), 3.84$ $(1 \mathrm{H}, \mathrm{d}, J=10.0 \mathrm{~Hz}), 3.96(1 \mathrm{H}, \mathrm{t}, J=8.5 \mathrm{~Hz}), 4.26(1 \mathrm{H}, \mathrm{d}$, $J=9.5 \mathrm{~Hz}), 4.31(1 \mathrm{H}, \mathrm{d}, J=11.0 \mathrm{~Hz}), 4.46(2 \mathrm{H}, \mathrm{t}, J=$ $12.0 \mathrm{~Hz}), 4.58(1 \mathrm{H}, \mathrm{d}, J=10.0 \mathrm{~Hz}), 4.62(2 \mathrm{H}, \mathrm{s}), 4.81(1 \mathrm{H}$, $\mathrm{d}, J=10.0 \mathrm{~Hz}), 4.83(1 \mathrm{H}, \mathrm{d}, J=10.5 \mathrm{~Hz}), 5.05\left(1 \mathrm{H}, \mathrm{dt}, J_{1}=\right.$ $\left.9.0 \mathrm{~Hz}, J_{2}=1.0 \mathrm{~Hz}\right), 5.18(2 \mathrm{H}, \mathrm{s}), 6.35(2 \mathrm{H}, \mathrm{d}, J=8.0 \mathrm{~Hz})$, $6.41(2 \mathrm{H}, \mathrm{d}, J=7.5 \mathrm{~Hz}), 6.67\left(1 \mathrm{H}, \mathrm{dd}, J_{1}=9.5 \mathrm{~Hz}, J_{2}=\right.$ $1.0 \mathrm{~Hz}), 6.95-7.30(25 \mathrm{H}), 8.28(1 \mathrm{H}, \mathrm{d}, J=5.0 \mathrm{~Hz}), 9.03$ $(1 \mathrm{H}, \mathrm{d}, J=8.0 \mathrm{~Hz}), 9.06(1 \mathrm{H}, \mathrm{d}, J=8.0 \mathrm{~Hz}), 10.31(1 \mathrm{H}, \mathrm{s}$, $\mathrm{NH}) .{ }^{13} \mathrm{C}$ NMR $\left(100 \mathrm{MHz}, \mathrm{CDCl}_{3}\right): 21.5\left(\mathrm{CH}_{3}\right), 66.6,67.0$, 71.7, 74.2, 75.6, $76.5\left(\mathrm{CH}_{2}\right), 76.4,77.9,79.7,80.4,83.7$ $\left(\mathrm{C}_{1^{\prime}}, \mathrm{C}_{2^{\prime}}, \mathrm{C}_{3^{\prime}}, \mathrm{C}_{4^{\prime}}, \mathrm{C}_{5^{\prime}}\right), 112.0,117.7,121.6,125.7,126.1$ (2C), 127.5-129.0, 134.0, 146.8 (C tert arom), 115.2, 116.3, $119.3,120.3,121.0,122.6,127.0,130.1,133.0,136.6$, $137.3,137.6,137.8,141.8,144.3,151.4$ (C quat arom), $169.3,169.4(\mathrm{C}=\mathrm{O})$.

4.1.26. 6-Benzyloxymethyl-5,7-dihydro-13,12-(3,4,6-tri$O$-benzyl- $\beta$-D-mannopyranose-1,2-diyl)-pyrido $\left[3^{\prime}, 2^{\prime}\right.$ : 4,5]pyrrolo[2,3-a] pyrrolo[3,4-c] carbazole-5,7-dione 27. To a solution of $26(15 \mathrm{mg}, 0.0145 \mathrm{mmol})$ in DMF $(1 \mathrm{~mL})$ was added $\mathrm{NaN}_{3}(10 \mathrm{mg}, 0.154 \mathrm{mmol})$. The mixture was stirred overnight at $70^{\circ} \mathrm{C}$. Water was added. After extraction with EtOAc, the organic phase was dried over $\mathrm{MgSO}_{4}$, the solvent was removed and the residue was purified by flash chromatography (eluent cyclohexane/ EtOAc 4:1 then $\mathrm{CH}_{2} \mathrm{Cl}_{2} / \mathrm{EtOAc}$ 9:1) to give 27 (11.6 mg, $0.0137 \mathrm{mmol}, 93 \%$ yield) as a yellow solid.

Compound 27. Mp 59-61 ${ }^{\circ} \mathrm{C}$. IR (KBr) $\nu_{\mathrm{C}=\mathrm{O}} 1700$, $1750 \mathrm{~cm}^{-1}$. Mass (ESI+) $[\mathrm{M}+\mathrm{Na}]^{+} 883 .{ }^{1} \mathrm{H}$ NMR $\left(400 \mathrm{MHz}, \mathrm{CDCl}_{3}\right): 3.34\left(1 \mathrm{H}, \mathrm{dd}, J_{1}=10.0 \mathrm{~Hz}, J_{2}=\right.$ $4.0 \mathrm{~Hz}), 3.47\left(1 \mathrm{H}, \mathrm{dd}, J_{1}=11.0 \mathrm{~Hz}, J_{2}=2.5 \mathrm{~Hz}, \mathrm{H}_{6^{\prime}}\right), 3.58$ $\left(1 \mathrm{H}, \mathrm{dd}, J_{1}=11.5 \mathrm{~Hz}, J_{2}=4.0 \mathrm{~Hz}, \mathrm{H}_{6^{\prime}}\right), 3.95\left(1 \mathrm{H}, \mathrm{m}, \mathrm{H}_{5^{\prime}}\right)$, $3.97(2 \mathrm{H}, \mathrm{s}), 4.11\left(1 \mathrm{H}, \mathrm{t}, J=8.5 \mathrm{~Hz}, \mathrm{H}_{4^{\prime}}\right), 4.30\left(1 \mathrm{H}, \mathrm{dd}, J_{1}=\right.$ $\left.9.0 \mathrm{~Hz}, J_{2}=3.0 \mathrm{~Hz}, \mathrm{H}_{3^{\prime}}\right), 4.56(1 \mathrm{H}, \mathrm{d}, J=11.0 \mathrm{~Hz}), 4.65$ $(2 \mathrm{H}, \mathrm{s}), 4.74(2 \mathrm{H}, \mathrm{s}), 4.84(1 \mathrm{H}, \mathrm{d}, J=11.0 \mathrm{~Hz}), 5.08(1 \mathrm{H}, \mathrm{s}$, $\left.\mathrm{H}_{2^{\prime}}\right), 5.11(1 \mathrm{H}, \mathrm{d}, J=3.5 \mathrm{~Hz}), 6.41\left(1 \mathrm{H}, \mathrm{s}, \mathrm{H}_{1^{\prime}}\right), 6.64(2 \mathrm{H}, \mathrm{d}$, $J=8.0 \mathrm{~Hz}), 6.91(2 \mathrm{H}, \mathrm{t}, J=7.5 \mathrm{~Hz}), 7.02(1 \mathrm{H}, \mathrm{t}, J=7.5 \mathrm{~Hz})$, $7.12(1 \mathrm{H}, \mathrm{t}, J=7.5 \mathrm{~Hz}), 7.15-7.35(15 \mathrm{H}, \mathrm{m}), 7.40(1 \mathrm{H}, \mathrm{t}$, $J=8.0 \mathrm{~Hz}), 7.47(1 \mathrm{H}, \mathrm{t}, J=8.0 \mathrm{~Hz}), 8.43-8.48(2 \mathrm{H}, \mathrm{m})$, $8.88(1 \mathrm{H}, \mathrm{d}, J=7.5 \mathrm{~Hz}), 8.91(1 \mathrm{H}, \mathrm{d}, J=6.5 \mathrm{~Hz}) .{ }^{13} \mathrm{C}$ NMR $\left(100 \mathrm{MHz}, \mathrm{CDCl}_{3}\right): 60.5,73.1,78.6,80.0,80.5\left(\mathrm{C}_{1^{\prime}}, \mathrm{C}_{2^{\prime}}\right.$, $\left.\mathrm{C}_{3^{\prime}}, \mathrm{C}_{4^{\prime}}, \mathrm{C}_{5^{\prime}}\right), 66.7,68.2,71.5,73.1,73.3,75.0\left(\mathrm{CH}_{2}\right), 114.5$,
$118.2,122.0,125.8,127.4-129.4,133.7,146.8$ (C tert arom), 111.0, 115.2, 120.3, 120.9, 124.5, 129.2, 131.3, 136.6, 137.7, 142.9, 151.8 (C quat arom), 169.3, 169.4 $(\mathrm{C}=\mathrm{O})$.

4.1.27. 5,7-Dihydro-13,12-( $\beta$-D-mannopyranose-1,2diyl)-6H-pyrido $\left[3^{\prime}, 2^{\prime}: 4,5\right]$ pyrrolo[ $[2,3-a]$ pyrrolo $[3,4-c]$ carbazole-5,7-dione 28. To a suspension of 27 (135 mg, $0.157 \mathrm{mmol})$ in $\mathrm{CH}_{2} \mathrm{Cl}_{2}(18 \mathrm{~mL})$ at $-78{ }^{\circ} \mathrm{C}$ was added a $1 \mathrm{M}$ solution of $\mathrm{BBr}_{3}$ in $\mathrm{CH}_{2} \mathrm{Cl}_{2}(3.16 \mathrm{~mL})$. The mixture was stirred at $-78{ }^{\circ} \mathrm{C}$ for $30 \mathrm{~min}$, then it was allowed to reach room temperature. After extraction with $\mathrm{EtOAc}$, the organic phase was dried over $\mathrm{MgSO}_{4}$ and the solvent was removed. The residue was dried under vacuum for $1 \mathrm{~h}$. To a solution of the residue $(56 \mathrm{mg})$ in THF $(6 \mathrm{~mL})$ was added $28 \%$ aqueous $\mathrm{NH}_{4} \mathrm{OH}(12 \mathrm{~mL})$. The mixture was stirred overnight at room temperature. The solvent was removed and the residue was purified by flash chromatography (eluent from EtOAc $100 \%$ to EtOAc/MeOH 95:5) to give 28 (20 mg, $0.0425 \mathrm{mmol}, 27 \%$ yield) as a yellow solid.

Compound 28. $\mathrm{Mp}>300{ }^{\circ} \mathrm{C}$. IR $(\mathrm{KBr}) \nu_{\mathrm{C}=\mathrm{O}} 1703$, $1747 \mathrm{~cm}^{-1}, \nu_{\mathrm{NH}, \mathrm{OH}} 3038-3619 \mathrm{~cm}^{-1}$. Mass (ESI + ) $[\mathrm{M}+\mathrm{H}]^{+}$471. HRMS $(\mathrm{FAB}+)[\mathrm{M}+\mathrm{H}]^{+}$, calcd for $\mathrm{C}_{25} \mathrm{H}_{18} \mathrm{~N}_{4} \mathrm{O}_{6}$ 471.1304, found 471.1291. ${ }^{1} \mathrm{H}$ NMR $\left(400 \mathrm{MHz}\right.$, DMSO- $\left.d_{6}\right): 3.30\left(1 \mathrm{H}, \mathrm{dd}, J_{1}=12.5 \mathrm{~Hz}, J_{2}=\right.$ $\left.5.5 \mathrm{~Hz}, \mathrm{H}_{6^{\prime}}\right), 3.55\left(1 \mathrm{H}, \mathrm{dd}, J_{1}=12.5 \mathrm{~Hz}, J_{2}=1.5 \mathrm{~Hz}, \mathrm{H}_{6^{\prime}}\right)$, $3.70\left(1 \mathrm{H}, \mathrm{d}, J=9.5 \mathrm{~Hz}, \mathrm{H}_{5^{\prime}}\right), 3.76\left(1 \mathrm{H}, \mathrm{m}, \mathrm{H}_{4^{\prime}}\right), 4.43(1 \mathrm{H}, \mathrm{t}$, $\left.J=5.5 \mathrm{~Hz}, \mathrm{OH}_{6^{\prime}}\right), 4.58\left(1 \mathrm{H}, \mathrm{m}, \mathrm{H}_{3^{\prime}}\right), 5.16(1 \mathrm{H}, \mathrm{d}, J=2.0 \mathrm{~Hz}$, $\left.\mathrm{H}_{2^{\prime}}\right), 5.60\left(1 \mathrm{H}\right.$, br s, $\left.\mathrm{OH}_{4^{\prime}}\right), 6.74\left(1 \mathrm{H}, \mathrm{d}, J=4.0 \mathrm{~Hz}, \mathrm{OH}_{3^{\prime}}\right)$, $6.90\left(1 \mathrm{H}, \mathrm{s}, \mathrm{H}_{1^{\prime}}\right), 7.47(1 \mathrm{H}, \mathrm{t}, J=7.5 \mathrm{~Hz}), 7.60\left(1 \mathrm{H}, \mathrm{dd}, J_{1}=\right.$ $\left.8.0 \mathrm{~Hz}, J_{2}=5.0 \mathrm{~Hz}\right), 7.64\left(1 \mathrm{H}, \mathrm{dt}, J_{1}=7.0 \mathrm{~Hz}, J_{2}=1.5 \mathrm{~Hz}\right)$, $8.68\left(1 \mathrm{H}, \mathrm{dd}, J_{1}=4.5 \mathrm{~Hz}, J_{2}=1.5 \mathrm{~Hz}\right), 8.84(1 \mathrm{H}, \mathrm{d}, J=$ $8.0 \mathrm{~Hz}), 8.94\left(1 \mathrm{H}, \mathrm{dd}, J_{1}=7.5 \mathrm{~Hz}, J_{2}=1.5 \mathrm{~Hz}\right), 9.08(1 \mathrm{H}, \mathrm{d}$, $J=8.5 \mathrm{~Hz}), 11.17(1 \mathrm{H}, \mathrm{s}, \mathrm{NH}) .{ }^{13} \mathrm{C} \mathrm{NMR}(100 \mathrm{MHz}$, DMSO- $\left.d_{6}\right): 60.2\left(\mathrm{C}_{6^{\prime}}\right), 64.3,65.8,72.3,79.5,80.9\left(\mathrm{C}_{1^{\prime}}\right.$, $\left.\mathrm{C}_{2^{\prime}}, \mathrm{C}_{3^{\prime}}, \mathrm{C}_{4^{\prime}}, \mathrm{C}_{5^{\prime}}\right), 109.3,113.6,117.0,120.9,121.4,123.4$, $129.1,131.1,143.0,151.0$ (C quat arom), 116.4, 118.0, $121.0,124.2,127.0,132.6,146.7$ (C tert arom), 170.7, 171.0 $(2 \mathrm{C}=\mathrm{O})$.

\section{References and notes}

1. Bush, J. A.; Long, B. H.; Catino, J. J.; Bradner, W. T.; Tomita, K. J. Antibiot. 1987, 40, 668-678.

2. Tamaoki, T.; Nomoto, H.; Takahashi, I.; Kato, Y.; Morimoto, M.; Tomita, F. Biochem. Biophys. Res. Commun. 1986, 135, 397-402.

3. Matson, J. A.; Claridge, C.; Bush, J. A.; Titus, J.; Bradner, W. T.; Doyle, T. W.; Horan, A. C.; Patel, M. J. Antibiot. 1989, $42,1547-1555$.

4. Takahashi, I.; Kobayashi, E.; Asano, K.; Yoshida, M.; Nakano, H. J. Antibiot. 1987, 40, 1782-1784.

5. Rodrigues Pereira, E.; Belin, L.; Sancelme, M.; Prudhomme, M.; Ollier, M.; Rapp, M.; Sevère, D.; Riou, J-F. ; Fabbro, D.; Meyer, T. J. Med. Chem. 1996, 39, 4471.

6. Moreau, P.; Gaillard, N.; Marminon, C.; Anizon, F.; Dias, N.; Baldeyrou, B.; Bailly, C.; Pierré, A.; Hickman, J.; Pfeiffer, B.; Renard, P.; Prudhomme, M. Bioorg. Med. Chem. 2003, 11, 4871. 
7. Prudhomme, M. Curr. Pharm. Des. 1997, 3, 265-290.

8. Marminon, C.; Pierré, A.; Pfeiffer, B.; Pérez, V.; Léonce, S.; Renard, P.; Prudhomme, M. Bioorg. Med. Chem. 2003, 11, 679-687.

9. Marminon, C.; Pierré, A.; Pfeiffer, B.; Pérez, V.; Léonce, S.; Joubert, A.; Bailly, C.; Renard, P.; Hickman, J.; Prudhomme, M. J. Med. Chem. 2003, 46, 609-622.

10. Anizon, F.; Moreau, P.; Sancelme, M.; Voldoire, A.; Prudhomme, M.; Ollier, M.; Sevère, D.; Riou, J-F. ; Bailly, C.; Fabbro, D.; Meyer, T.; Aubertin, A-M. Bioorg. Med. Chem. 1998, 6, 1597-1604.

11. Marminon, C.; Anizon, F.; Moreau, P.; Léonce, S.; Pierré, A.; Pfeiffer, B.; Renard, P.; Prudhomme, M. J. Med. Chem. 2002, 45, 1330-1339.

12. Messaoudi, S.; Anizon, F.; Pfeiffer, B.; Golsteyn, R.; Prudhomme, M. Tetrahedron Lett. 2004, 45, 4643-4647.

13. Gray, N.; Détivaud, L.; Doerig, C.; Meijer, L. Curr. Med. Chem. 1999, 6, 859-875.

14. Zhao, B.; Bower, M. J.; McDewitt, P. J.; Zhao, H.; Davis, S. T.; Johanson, K. O.; Green, S. M.; Concha, N. O.; Zhou, B. B. J. Biol. Chem. 2002, 277, 46609-46615.
15. Anizon, F.; Moreau, P.; Sancelme, M.; Laine, W.; Bailly, C.; Prudhomme, M. Bioorg. Med. Chem. 2003, 11, 3709-3722.

16. Prudhomme, M. Curr. Med. Chem. Anti-Cancer Agents 2004, 4, 509-521.

17. Bovin, N. V.; Zurabyan, S. E.; Khorlin, A. Y. Carbohydr. Res. 1981, 98, 25-35.

18. Timer, C. M.; van Straten, N. C. R.; van der Marel, G. A.; van Boom, J. H. J. Carbohydr. Chem. 1998, 17, 471-487.

19. Takahashi, T.; Ebata, S.; Yamada, H. Synlett 1998, 381-382.

20. Routier, S.; Ayerbe, N.; Mérour, J.-Y.; Coudert, G.; Bailly, C.; Pierré, A.; Pfeiffer, B.; Caignard, D.-H.; Renard, P. Tetrahedron 2002, 58, 6621-6630.

21. Alonso, R. A.; Vite, G. D.; McDevitt, R. E.; Fraser-Reid, B. J. Org. Chem. 1992, 57, 573-584.

22. Marples, B. A.; Muxworthy, J. P.; Baggaley, K. H. Synlett $1992,646$.

23. Csuk, R.; Dörr, P. Tetrahedron 1994, 50, 9983-9988.

24. Faul, M. M.; Winneroski, L. L.; Krumrich, C. A. J. Org. Chem. 1999, 64, 2465-2470. 